\title{
Photooxidation of pinonaldehyde at ambient conditions investigated in the atmospheric simulation chamber SAPHIR
}

\author{
Michael Rolletter $^{1}$, Marion Blocquet ${ }^{1}{ }^{\text {a }}$, Martin Kaminski ${ }^{1, b}$, Birger Bohn ${ }^{1}$, Hans-Peter Dorn ${ }^{1}$, \\ Andreas Hofzumahaus ${ }^{1}$, Frank Holland ${ }^{1}$, Xin Li ${ }^{1, \mathrm{c}}$, Franz Rohrer ${ }^{1}$, Ralf Tillmann ${ }^{1}$, Robert Wegener ${ }^{1}$, \\ Astrid Kiendler-Scharr ${ }^{1}$, Andreas Wahner ${ }^{1}$, and Hendrik Fuchs ${ }^{1}$ \\ ${ }^{1}$ Institute of Energy and Climate Research, IEK-8: Troposphere, Forschungszentrum Jülich GmbH, Jülich, Germany \\ anow at: Ministère de l'Education Nationale et de la Jeunesse, 110 rue de Grenelle, 75357 Paris SP 07, France \\ bnow at: Federal Office of Consumer Protection and Food Safety, Department 5: Method Standardization, \\ Reference Laboratories, Resistance to Antibiotics, Berlin, Germany \\ ${ }^{c}$ now at: College of Environmental Sciences and Engineering, Peking University, Beijing, China
}

Correspondence: Hendrik Fuchs (h.fuchs@fz-juelich.de)

Received: 31 March 2020 - Discussion started: 14 April 2020

Revised: 22 July 2020 - Accepted: 24 September 2020 - Published: 14 November 2020

\begin{abstract}
The photooxidation of pinonaldehyde, one product of the $\alpha$-pinene degradation, was investigated in the atmospheric simulation chamber SAPHIR under natural sunlight at low NO concentrations $(<0.2 \mathrm{ppbv})$ with and without an added hydroxyl radical $(\mathrm{OH})$ scavenger. With a scavenger, pinonaldehyde was exclusively removed by photolysis, whereas without a scavenger, the degradation was dominated by reaction with $\mathrm{OH}$. In both cases, the observed rate of pinonaldehyde consumption was faster than predicted by an explicit chemical model, the Master Chemical Mechanism (MCM, version 3.3.1). In the case with an $\mathrm{OH}$ scavenger, the observed photolytic decay can be reproduced by the model if an experimentally determined photolysis frequency is used instead of the parameterization in the MCM. A good fit is obtained when the photolysis frequency is calculated from the measured solar actinic flux spectrum, absorption cross sections published by Hallquist et al. (1997), and an effective quantum yield of 0.9. The resulting photolysis frequency is 3.5 times faster than the parameterization in the MCM. When pinonaldehyde is mainly removed by reaction with $\mathrm{OH}$, the observed $\mathrm{OH}$ and hydroperoxy radical $\left(\mathrm{HO}_{2}\right)$ concentrations are underestimated in the model by a factor of 2 . Using measured $\mathrm{HO}_{2}$ as a model constraint brings modeled and measured $\mathrm{OH}$ concentrations into agreement. This suggests that the chemical mechanism includes all relevant $\mathrm{OH}$-producing reactions but is missing a source for $\mathrm{HO}_{2}$. The missing $\mathrm{HO}_{2}$ source strength of ( 0.8 to 1.5$) \mathrm{ppbvh}^{-1}$ is similar to the rate
\end{abstract}

of the pinonaldehyde consumption of up to $2.5 \mathrm{ppbvh}^{-1}$. When the model is constrained by $\mathrm{HO}_{2}$ concentrations and the experimentally derived photolysis frequency, the pinonaldehyde decay is well represented. The photolysis of pinonaldehyde yields $0.18 \pm 0.20$ formaldehyde molecules at $\mathrm{NO}$ concentrations of less than $200 \mathrm{pptv}$, but no significant acetone formation is observed. When pinonaldehyde is also oxidized by $\mathrm{OH}$ under low $\mathrm{NO}$ conditions (maximum $80 \mathrm{pptv}$ ), yields of acetone and formaldehyde increase over the course of the experiment from 0.2 to 0.3 and from 0.15 to 0.45 , respectively. Fantechi et al. (2002) proposed a degradation mechanism based on quantum-chemical calculations, which is considerably more complex than the MCM scheme and contains additional reaction pathways and products. Implementing these modifications results in a closure of the model-measurement discrepancy for the products acetone and formaldehyde, when pinonaldehyde is degraded only by photolysis. In contrast, the underprediction of formed acetone and formaldehyde is worsened compared to model results by the MCM, when pinonaldehyde is mainly degraded in the reaction with $\mathrm{OH}$. This shows that the current mechanisms lack acetone and formaldehyde sources for low NO conditions like in these experiments. Implementing the modifications suggested by Fantechi et al. (2002) does not improve the model-measurement agreement of $\mathrm{OH}$ and $\mathrm{HO}_{2}$. 


\section{Introduction}

Globally, emissions of biogenic non-methane volatile organic compounds (NMVOCs) in the atmosphere are 10 times higher than emissions of anthropogenic NMVOCs (Guenther et al., 2012). Of these emissions, monoterpenes (C10 compounds) represent approximately $15 \%$ (Guenther et al., 2012) of the total emissions. Monoterpenes are mainly oxidized in the atmosphere by ozonolysis or their reaction with the hydroxyl radical $(\mathrm{OH})$ during daytime. However, oxidation by the nitrate radical $\left(\mathrm{NO}_{3}\right)$ during nighttime can also be of importance enhanced by nocturnal monoterpene emissions (Calogirou et al., 1999; Atkinson and Arey, 2003). Oxidation products significantly contribute to the global production of, for example, acetone (Jacob et al., 2002). In addition, low-volatility organic oxidation products play an important role for the formation of secondary organic aerosol (SOA) (Kanakidou et al., 2000). The oxidation of monoterpenes and their oxidation products is also of importance for the tropospheric ozone production (Schwantes et al., 2020).

Field measurements indicate that there is a lack of understanding of the radical chemistry connected to the photooxidation of monoterpenes (e.g., Peeters et al., 2001; Capouet et al., 2004, and references therein). Hydroperoxy radical $\left(\mathrm{HO}_{2}\right)$ concentrations measured in environments dominated by monoterpenes are not well understood by model calculations, for example, in a campaign performed in the foothills of the Rocky Mountains (Kim et al., 2013) and in a boreal forest in Finland (Hens et al., 2014). In these campaigns, modeled $\mathrm{HO}_{2}$ concentrations were lower by a factor of 2 and 2.5 , respectively, compared to measurements. Chamber studies investigating the oxidation of $\alpha$ - and $\beta$-pinene also gave higher $\mathrm{HO}_{2}$ concentrations than model calculations suggest (Kaminski et al., 2017; Rolletter et al., 2019).

Among the monoterpenes, $\alpha$-pinene is the most abundant (Guenther et al., 2012). Pinonaldehyde is one of the first-generation oxidation products. In the $\alpha$-pinene photooxidation, initially three different peroxy radicals $\left(\mathrm{RO}_{2}\right)$ are formed, and two of them eventually form pinonaldehyde. Several field campaigns reported pinonaldehyde concentrations measured on filter samples (Kavouras et al., 1999; Alves et al., 2002; Boy et al., 2004; Cahill et al., 2006; Rissanen et al., 2006; Herckes et al., 2006; Plewka et al., 2006) or in the analysis of rain and snow samples (Satsumabayashi et al., 2001). Only a few studies reported ambient gas-phase concentrations of pinonaldehyde. Field studies in the San Bernardino National Forest, California (Yu et al., 1999), and the German Fichtelgebirge (Müller et al., 2006) reported pinonaldehyde concentrations in the gas phase of approximately 0.15 ppbv. Another study by Cahill et al. (2006) conducted in the Sierra Nevada Mountains of California measured 0.05 to $0.30 \mathrm{ppbv}$ gaseous pinonaldehyde. Pinonaldehyde yields from the photochemical degradation of $\alpha$-pinene with $\mathrm{OH}$ were measured in laboratory experiments ranging from $6 \%$ to $87 \%$ (Larsen et al., 2001; Noziére et al., 1999).
The high variability could be due to different chemical conditions with partially high reactant concentrations used in these experiments. A recent study in the atmospheric simulation chamber SAPHIR used ambient reactant concentrations ( $[\alpha-$ pinene $] \leq 3.8 \mathrm{ppbv},[\mathrm{NO}]<120 \mathrm{pptv},(310 \pm 5) \mathrm{K})$ and reported a low yield of $5 \%$ (Rolletter et al., 2019). As currently implemented in the Master Chemical Mechanism (MCM, 2017; Jenkin et al., 1997; Saunders et al., 2003), pinonaldehyde is formed with a total yield of $84 \%$. In contrast, a theory-based study by Vereecken et al. (2007) suggested a different branching ratio of initial $\mathrm{RO}_{2}$ and additional reaction channels which lead to pinonaldehyde yields of $60 \%$ in total for low atmospheric NO conditions ( $\leq 1 \mathrm{ppbv} \mathrm{NO}$ ). Our previous study (Rolletter et al., 2019) showed that further adjustment of the initial $\mathrm{RO}_{2}$ branching ratio in a mechanism based on Vereecken et al. (2007) was necessary to explain the low measured pinonaldehyde yield of $5 \%$ for conditions similar to the experiments discussed here. A similar change in $\mathrm{RO}_{2}$ branching ratios was found in an experimental study by Xu et al. (2019).

The photochemistry of pinonaldehyde has been investigated in only a few experimental studies (Noziére et al., 1999; Jaoui and Kamens, 2003; Capouet et al., 2004) in addition to a few theoretical studies (Glasius et al., 1997; Vereecken and Peeters, 2002; Fantechi et al., 2002; Dash and Rajakumar, 2012). The pinonaldehyde degradation during daytime is controlled by photolysis and the reaction with $\mathrm{OH}$ radicals, resulting in an atmospheric lifetime on the order of a few hours due to its fast reaction with $\mathrm{OH}$ (Atkinson et al., 2004). The lifetime of pinonaldehyde with respect to photodissociation strongly depends on the season and the latitude but can be comparable to the reaction with $\mathrm{OH}$ (Hallquist et al., 1997). The main oxidation products (Fig. 1) of the photolysis and $\mathrm{OH}$ reactions are norpinonaldehyde (NORPINAL; names are taken from the MCM), pinonic acid (PINONIC), perpinonic acid (PERPINONIC), formaldehyde (HCHO), and acetone. So far there has been only one study by Noziére et al. (1999) reporting yields for the reaction with $\mathrm{OH}$ for $\mathrm{HCHO}$ and acetone of $(152 \pm 56) \%$ and $(15 \pm 7) \%$, respectively.

A simplified oxidation scheme of pinonaldehyde is shown in Fig. 1. As implemented in the MCM, the photolysis of pinonaldehyde (PINAL) leads to dissociation in $\mathrm{HCO}$ and an organic radical, both of which react with $\mathrm{O}_{2}$ to form $\mathrm{CO}$, $\mathrm{HO}_{2}$, and the peroxy radical $\mathrm{C} 96 \mathrm{O} 2$.

$\mathrm{PINAL}+h v+\mathrm{O}_{2} \rightarrow \mathrm{C} 96 \mathrm{O} 2+\mathrm{CO}+\mathrm{HO}_{2}$

The oxidation of pinonaldehyde by $\mathrm{OH}$ is initiated by $\mathrm{H}$ abstraction mainly at the aldehyde group forming primary $\mathrm{RO}_{2}$. In the MCM, an acyl peroxy radical (C96CO3) and 


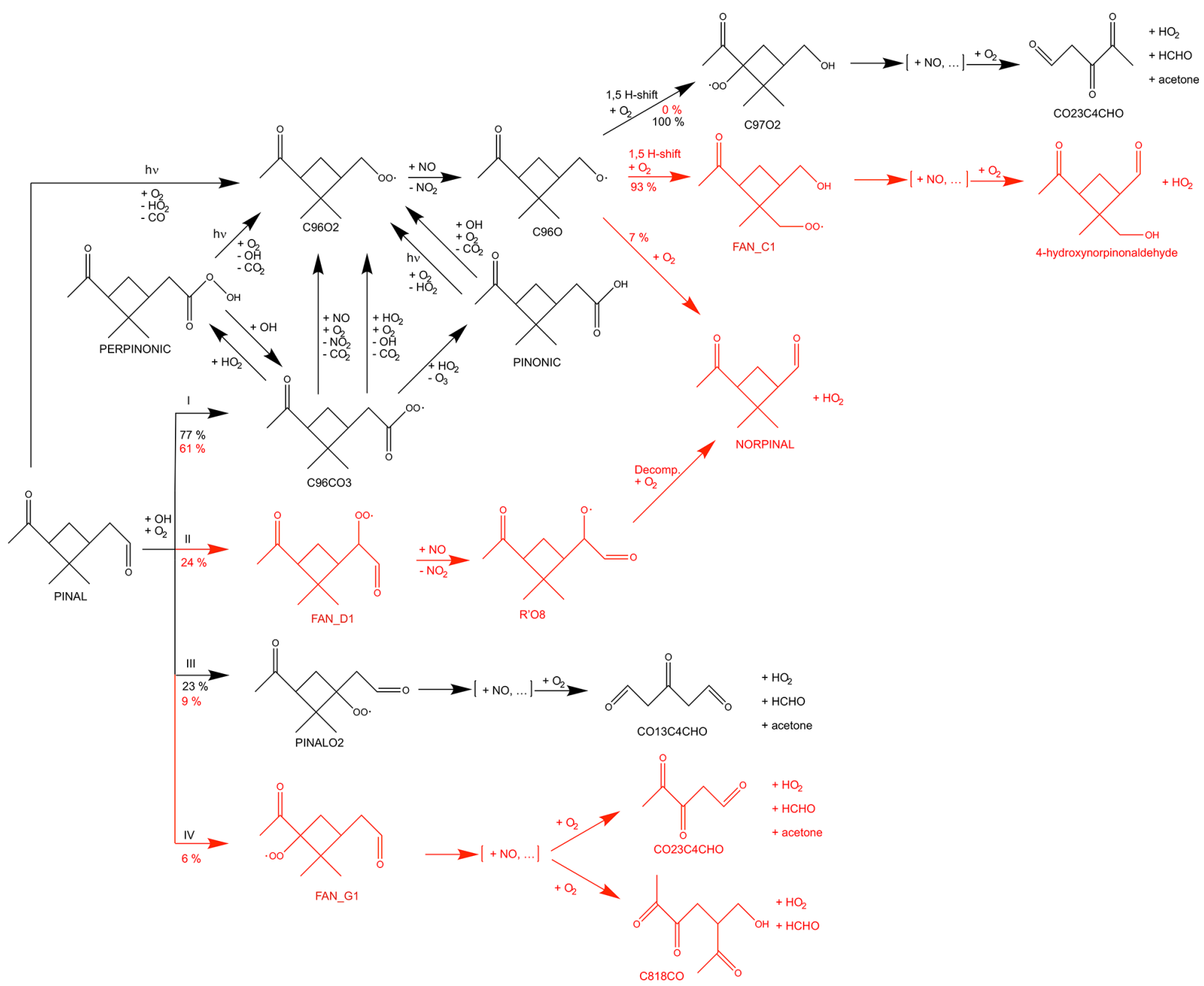

Figure 1. Simplified oxidation scheme of pinonaldehyde as described in the MCM (black) and modifications in the model derived by Fantechi et al. (2002) (red). [+NO, ...] represents reaction sequences that are initiated by peroxy radical reactions with NO and eventually form carbonyl compounds plus $\mathrm{HO}_{2}$. Possible reactions of $\mathrm{RO}_{2}$ with other $\mathrm{RO}_{2}$ are not shown. $\mathrm{RO}_{2}+\mathrm{HO}_{2}$ reactions are only shown for the major peroxy radical C96CO3. See text for details.

PINALO2 are formed.

$\mathrm{PINAL}+\mathrm{OH}+\mathrm{O}_{2} \rightarrow \mathrm{C} 96 \mathrm{CO} 3$ (yield : 0.77)

$\mathrm{PINAL}+\mathrm{OH}+\mathrm{O}_{2} \rightarrow$ PINALO2 (yield : 0.23 )

In the presence of high nitric oxide (NO) concentrations, $\mathrm{RO}_{2}$ reacts with $\mathrm{NO}$ and forms either alkoxy radicals (RO) or organic nitrate compounds $\left(\mathrm{RONO}_{2}\right)$. In the reaction forming an alkoxy radical, $\mathrm{NO}$ is converted to $\mathrm{NO}_{2}$ and $\mathrm{HO}_{2}$ to $\mathrm{OH}$, respectively. The alkoxy radical subsequently reacts with $\mathrm{O}_{2}$ to form a carbonyl compound and $\mathrm{HO}_{2}$, decomposes, or isomerizes. At low $\mathrm{NO}$ concentrations, $\mathrm{RO}_{2}$ reactions with $\mathrm{HO}_{2}$ terminating the radical chain reactions and forming stable hydroxyperoxides $(\mathrm{ROOH})$ increase in importance. Formed stable organic products of $\mathrm{RO}_{2}+\mathrm{NO}$ and $\mathrm{RO}_{2}+\mathrm{HO}_{2}$ reactions can further react with $\mathrm{OH}$ or photolyze.
The reaction of the most important $\mathrm{RO}_{2}$ radical, $\mathrm{C} 96 \mathrm{CO} 3$, with $\mathrm{HO}_{2}$ can either directly form the same product $(\mathrm{C} 96 \mathrm{O} 2)$ as its reaction with $\mathrm{NO}$ or can form the stable products, i.e., pinonic and perpinonic acid. Subsequently, pinonic and perpinonic acid are photolyzed or react with $\mathrm{OH}$, and thereby produce the peroxy radical $\mathrm{C} 96 \mathrm{O} 2$ again. Similarly, other $\mathrm{RO}_{2}+\mathrm{HO}_{2}$ reactions not shown in Fig. 1 produce the same species that are produced by $\mathrm{RO}_{2}+\mathrm{NO}$ reactions.

In the atmosphere, the peroxy radical $\mathrm{C} 96 \mathrm{O} 2$ can react with nitric oxide (NO) to form the corresponding alkoxy radical C96O.

$\mathrm{C} 96 \mathrm{O} 2+\mathrm{NO} \rightarrow \mathrm{C} 96 \mathrm{O}+\mathrm{NO}_{2}$ 
C96O undergoes isomerization or decomposition reactions producing formaldehyde, acetone, or 3,4-dioxopentanal (CO23C4CHO).

The main products of the subsequent chemistry of the other peroxy radical PINALO2, including multiple reactions with $\mathrm{NO}$ and decomposition reactions, are $\mathrm{HO}_{2}$, a tricarbonyl compound, acetone, and formaldehyde.

In contrast to the MCM, the theoretical study by Fantechi et al. (2002) predicts other decomposition reactions of products of the $\mathrm{RO}_{2}+\mathrm{NO}$ reaction (Fig. 1). Whereas other theory-based studies investigated the reaction rate of pinonaldehyde $+\mathrm{OH}$ (Glasius et al., 1997) and the probability of $\mathrm{H}$-abstraction by $\mathrm{OH}$ at various sites of pinonaldehyde (Vereecken and Peeters, 2002; Dash and Rajakumar, 2012), Fantechi et al. (2002) also analyzed the subsequent chemistry of the initially formed organic peroxy radicals. Instead of forming acetone and formaldehyde in the further degradation of C96O, Fantechi et al. (2002) suggest that the main fraction of $\mathrm{C} 96 \mathrm{O}$ undergoes a series of isomerization reactions and reactions with NO forming 4hydroxynorpinonaldehyde. In contrast to the MCM, the fourmembered ring structure is retained in the formed products. A small fraction $(\sim 7 \%)$ directly forms norpinonaldehyde (NORPINAL) after $\mathrm{H}$-abstraction by $\mathrm{O}_{2}$. The modifications by Fantechi et al. (2002) are limited to $\mathrm{RO}_{2}+\mathrm{NO}$ chemistry, and no detailed analysis of $\mathrm{RO}_{2}+\mathrm{HO}_{2}$ reactions was done in their work. Nevertheless, modifications suggested by Fantechi et al. (2002) also affect $\mathrm{RO}_{2}+\mathrm{HO}_{2}$ chemistry if products from these reactions are the same as from the reaction of $\mathrm{RO}_{2}+\mathrm{NO}$ as implemented in the MCM. In the model by Fantechi et al. (2002) some $\mathrm{RO}_{2}+\mathrm{NO}$ reactions also led to the formation of organic nitrates with yields between $14 \%$ and $28 \%$, which lower the yield of formed $\mathrm{HO}_{2}$ and carbonyl compounds.

Fantechi et al. (2002) proposed two additional relevant (yields $>5 \%$ ) peroxy radicals formed by the initial $\mathrm{OH}$ attack. Accordingly, the yields of $\mathrm{C} 96 \mathrm{CO} 3$ and PINALO2 are changed from $77 \%$ to $61 \%$ and $23 \%$ to $9 \%$ compared to the MCM, respectively. The first additional reaction channel with a branching ratio of $24 \%$ leads to a formation of norpinonaldehyde. The second additional reaction channel with only a minor contribution of $6 \%$ forms in the subsequent chemistry acetone, formaldehyde, and a tri-carbonylhydroxy compound.

In this work, the photochemistry of pinonaldehyde was investigated under controlled atmospheric conditions, including atmospherically reactant concentrations and natural sunlight in the outdoor chamber SAPHIR (Simulation of Atmospheric PHotochemistry In a large Reaction Chamber), at Forschungszentrum Jülich. This study focuses on (a) the determination of the pinonaldehyde photolysis frequency, (b) quantification of $\mathrm{HO}_{\mathrm{x}}\left(=\mathrm{OH}+\mathrm{HO}_{2}\right)$ radicals in the $\mathrm{OH}-$ oxidation of pinonaldehyde, and (c) the determination of acetone and formaldehyde yields of both photolysis and $\mathrm{OH}$ oxidation. Measurements of pinonaldehyde, degradation prod- ucts, and $\mathrm{HO}_{\mathrm{X}}$ radicals are compared to model calculations applying the Master Chemical Mechanism v3.3.1. Sensitivity model runs are performed including reaction pathways and yields suggested by the theoretical study of Fantechi et al. (2002), and the impact of the proposed mechanism on concentrations of organic compounds and $\mathrm{HO}_{\mathrm{x}}$ radicals is analyzed.

\section{Methods}

\subsection{Atmospheric simulation chamber SAPHIR}

Details of the SAPHIR chamber can be found elsewhere (e.g., Rohrer et al., 2005; Bohn et al., 2005) and the chamber is only briefly described here. It is of cylindrical shape (18 $\mathrm{m}$ length, $5 \mathrm{~m}$ diameter and $270 \mathrm{~m}^{3}$ volume) and is made of a double-wall Teflon (FEP) film. The FEP ensures inertness of the surfaces and minimizes wall effects. This outdoor chamber allows for studying the photochemical reactions under natural sunlight because the FEP film is transmissive for the entire solar spectrum. The chamber is equipped with a shutter system that can shield the chamber from sunlight.

Ultra-pure synthetic air used in the experiments is mixed from liquid nitrogen and oxygen (Linde, purity $>99.9999 \%$ ). The pressure inside the chamber is slightly (30 Pa) above ambient pressure to prevent impurities from ambient air leaking into the chamber. Air that is consumed by instruments or is lost due to small leakages is replenished to keep a constant pressure. The replenishment flow is in the range of 9 to $12 \mathrm{~m}^{3} \mathrm{~h}^{-1}$, leading to a dilution of trace gases of $3 \% \mathrm{~h}^{-1}$ to $4 \% \mathrm{~h}^{-1}$. Rapid mixing of air is ensured by the operation of two fans inside the chamber.

In the sunlit chamber, there are small sources for nitrous acid (HONO), formaldehyde (HCHO), and acetone. Their formation rates depend on the intensity of solar radiation, relative humidity, and temperature (Rohrer et al., 2005). The photolysis of HONO is the major primary source for nitrogen oxides and $\mathrm{OH}$. Approximately $250 \mathrm{pptvh}^{-1} \mathrm{NO}_{\mathrm{x}}$, $200 \mathrm{pptv} \mathrm{h}^{-1} \mathrm{HCHO}$, and $100 \mathrm{pptv} \mathrm{h}^{-1}$ acetone were formed in the experiments in this study.

\subsection{Instrumentation}

An overview of used instruments and their $1 \sigma$ accuracies and precision is given in Table 1.

$\mathrm{OH}$ radicals were measured by laser-induced fluorescence (LIF). The instrument operated at the SAPHIR chamber has been described elsewhere (e.g., Holland et al., 2003; Fuchs et al., 2012). Chamber air is sampled through an inlet nozzle into a low-pressure measurement cell, where $\mathrm{OH}$ is excited by pulsed laser radiation at $308 \mathrm{~nm}$. Its fluorescence is subsequently detected by gated photon counting. In addition, $\mathrm{HO}_{2}$ radicals are indirectly detected after chemical conversion to OH by NO in another measurement cell (Fuchs et al., 2011). The instrument is calibrated by a radical source, in which $\mathrm{OH}$ 
Table 1. Instrumentation for radical and trace gas detection during the pinonaldehyde oxidation experiments.

\begin{tabular}{|c|c|c|c|c|}
\hline & Technique & $\begin{array}{r}\text { Time } \\
\text { resolution }\end{array}$ & $\begin{array}{r}1 \sigma \\
\text { precision }\end{array}$ & $\begin{array}{r}1 \sigma \\
\text { accuracy }\end{array}$ \\
\hline $\mathrm{OH}$ & $\begin{array}{l}\text { DOAS }^{\text {a }} \text { (Dorn et al., 1995a; } \\
\text { Hausmann et al., 1997; Schlosser et al., 2007) }\end{array}$ & $205 \mathrm{~s}$ & $0.8 \times 10^{6} \mathrm{~cm}^{-3}$ & $6.5 \%$ \\
\hline $\mathrm{OH}$ & $\begin{array}{l}\text { LIF }^{\text {b }} \\
\text { (Holland et al., 2003; Fuchs et al., 2012) }\end{array}$ & $47 \mathrm{~s}$ & $0.3 \times 10^{6} \mathrm{~cm}^{-3}$ & $13 \%$ \\
\hline $\mathrm{HO}_{2}$ & $\begin{array}{l}\text { LIF }^{\mathrm{b}} \\
\text { (Fuchs et al., 2011) }\end{array}$ & $47 \mathrm{~s}$ & $1.5 \times 10^{7} \mathrm{~cm}^{-3}$ & $16 \%$ \\
\hline NO & $\begin{array}{l}\text { Chemiluminescence } \\
\text { (Rohrer and Brüning, 1992) }\end{array}$ & $180 \mathrm{~s}$ & 4 pptv & $5 \%$ \\
\hline $\mathrm{NO}_{2}$ & $\begin{array}{l}\text { Chemiluminescence } \\
\text { (Rohrer and Brüning, 1992) }\end{array}$ & $180 \mathrm{~s}$ & $2 \mathrm{pptv}$ & $5 \%$ \\
\hline $\mathrm{O}_{3}$ & $\begin{array}{l}\text { UV absorption } \\
\text { (Ansyco) }\end{array}$ & $10 \mathrm{~s}$ & $5 \mathrm{ppbv}$ & $5 \%$ \\
\hline $\begin{array}{l}\text { Pinonaldehyde, } \\
\text { acetone }\end{array}$ & $\begin{array}{l}\text { PTR-TOF-MS } \\
\text { (Lindinger et al., 1998) }\end{array}$ & $30 \mathrm{~s}$ & $15 \mathrm{pptv}$ & $6 \%$ \\
\hline Acetone & $\begin{array}{l}\text { GC-FID } \\
\text { (Kaminski et al., 2017) }\end{array}$ & $30 \mathrm{~min}$ & $20 \mathrm{pptv}$ & $5 \%$ \\
\hline $\mathrm{HCHO}$ & $\begin{array}{l}\text { Hantzsch monitor } \\
\text { (AeroLaser) }\end{array}$ & $120 \mathrm{~s}$ & 20 pptv & $5 \%$ \\
\hline $\mathrm{HCHO}$ & DOAS $^{\mathrm{a}}$ & $100 \mathrm{~s}$ & $20 \%$ & $10 \%$ \\
\hline HONO & $\begin{array}{l}\text { LOPAP }^{\mathrm{e}} \\
\text { (Li et al., 2014) }\end{array}$ & $300 \mathrm{~s}$ & $1.3 \mathrm{pptv}$ & $13 \%$ \\
\hline $\begin{array}{l}\text { Photolysis } \\
\text { frequencies }\end{array}$ & $\begin{array}{l}\text { Spectroradiometer } \\
\text { (Bohn et al., 2005) }\end{array}$ & $60 \mathrm{~s}$ & $10 \%$ & $10 \%$ \\
\hline
\end{tabular}

${ }^{a}$ Differential Optical Absorption Spectroscopy. ${ }^{b}$ Laser-Induced Fluorescence. ${ }^{c}$ Proton Transfer Reaction Time-Of-Flight Mass Spectrometry.

${ }^{\mathrm{d}}$ Gas Chromatography Flame Ionization Detector. ${ }^{\mathrm{e}}$ Long-Path Absorption Photometer.

and $\mathrm{HO}_{2}$ are produced by water vapor photolysis at $185 \mathrm{~nm}$ (Fuchs et al., 2011).

Interferences can occur in the $\mathrm{HO}_{2}$ measurements because of concurrent conversion of specific $\mathrm{RO}_{2}$ radicals that produce $\mathrm{OH}$ in the reaction with $\mathrm{NO}$ on a similar timescale to $\mathrm{HO}_{2}$ (Fuchs et al., 2011; Whalley et al., 2013; Lew et al., 2018). Because the conversion of $\mathrm{RO}_{2}$ requires at least two reaction steps with $\mathrm{NO}$, in contrast to $\mathrm{HO}_{2}$ for which only one reaction step leads to the formation of $\mathrm{OH}$, this interference can be minimized if the conversion efficiency of $\mathrm{HO}_{2}$ is below $10 \%$. This can be achieved by adjusting the NO concentration in the $\mathrm{HO}_{2}$ cell. This was done in this study so that it can be assumed that potential interferences in the $\mathrm{HO}_{2}$ detection were negligible.

In addition, $\mathrm{OH}$ was measured by differential optical absorption spectrometry (DOAS; Dorn et al., 1995b), which is an absolute measurement technique. Measured $\mathrm{OH}$ concentrations of both instruments agreed on average within $15 \%$, similar to results in previous experiments (Fuchs et al., 2012).

Organic compounds were measured by proton transfer reaction time-of-flight mass spectrometry (PTR-TOF-MS; Lindinger et al., 1998; Jordan et al., 2009) and by gas chromatography that was coupled to a flame ionization detector (GC-FID). The PTR-TOF-MS was calibrated for pinon- aldehyde using a diffusion source (Gautrois and Koppmann, 1999) and for acetone using a gas standard. An internal standard (tetrachloro-ethylene) was added to the GC-FID sample flow to monitor changes in the sensitivity of the calibration with a calibration standard (Apel 8). Formaldehyde was measured by a Hantzsch instrument and by DOAS. The Hantzsch instrument was calibrated using liquid $\mathrm{HCHO}$ standards.

Photolysis frequencies $(j)$ of $\mathrm{NO}_{2}, \mathrm{HONO}, \mathrm{O}_{3}$, and pinonaldehyde were calculated from actinic flux density spectra that are derived from measurements of total and diffuse spectral actinic flux densities outside the chamber. From these measurements, direct sun contributions are calculated. The direct and diffuse actinic flux densities are used as input for a model that calculates mean chamber spectra by taking into account the time-dependent effects of shadings of the chamber steel frame and the transmittance of the Teflon film which is $>0.8$ in the complete solar spectral range (Bohn and Zilken, 2005). Mean photolysis frequencies are then calculated by the following equation:

$j=\int \sigma(\lambda) \phi(\lambda) F_{\lambda}(\lambda) \mathrm{d} \lambda$,

where $\sigma$ is the absorption cross section, $\phi$ is the quantum yield, and $F$ is the actinic flux. The absorption cross sections and quantum yields of $\mathrm{NO}_{2}, \mathrm{HONO}$, and $\mathrm{O}_{3}$ used for the cal- 
culations of photolysis frequencies are taken from the literature (Mérienne et al., 1995; Troe, 2000; Stutz et al., 2000; Daumont et al., 1992; Matsumi et al., 2002). The method is regularly evaluated by dedicated experiments using the chamber as a chemical actinometer (Bohn et al., 2005). The pinonaldehyde photolysis frequency is discussed in more detail in Sect. 4.1.

$\mathrm{NO}$ and $\mathrm{NO}_{2}$ were measured by chemiluminescence (Eco Physics), water vapor mixing ratios were measured by a cavity ring-down instrument (Picarro), and ozone $\left(\mathrm{O}_{3}\right)$ was measured by an UV absorption instrument (Ansyco).

\subsection{Experimental procedure}

Before the experiment, the chamber was flushed with dry, synthetic air to dilute trace gases from previous experiments below the detection limits of the instruments. A total of 20 ppmv of $\mathrm{CO}_{2}$ was injected as a dilution tracer in the beginning of each experiment. Water from a Milli-Q device was boiled and flushed into the chamber together with a high flow of synthetic air $\left(150 \mathrm{~m}^{3} \mathrm{~h}^{-1}\right)$. The chamber was only humidified in the beginning of an experiment reaching initial water vapor concentrations of about $2 \%$, which decreased over the course of an experiment due to the dilution with dry synthetic air.

Pinonaldehyde (Orgentis chemicals, 98.2\%) was heated in a glass vial, and the vapor was flushed together with a small flow of dry nitrogen into the chamber using a short Teflon tube. After the injection had been stopped, the sample line was removed to avoid further evaporation of pinonaldehyde from the injection system into the chamber. The initial pinonaldehyde concentrations were 6.5 and 16.5 ppbv in the experiments on 17 and 18 July 2014, respectively. The chamber roof was opened after a stable pinonaldehyde concentration was observed by the PTR-TOF-MS instrument.

In one experiment (18 July 2014), 2500 ppbv of cyclohexane was additionally injected after the humidification. Cyclohexane served as scavenger for $\mathrm{OH}$ in this experiment in order to study the pinonaldehyde photolysis independently from its reaction with $\mathrm{OH}$.

In the other experiment (17 July 2014), 70 ppbv of ozone produced from a silent discharge ozonizer (O3Onia) was injected after humidification so that a low NO concentration (maximum 80 pptv) was obtained during the experiment. In this experiment, approximately $20 \%$ of reacted pinonaldehyde was photolyzed, and the remaining $80 \%$ reacted with $\mathrm{OH}$. The reaction of pinonaldehyde with ozone is very slow $\left(k=(8.9 \pm 1.4) \times 10^{-20} \mathrm{~cm}^{3} \mathrm{~s}^{-1}\right.$, Glasius et al., 1997), and therefore ozonolysis reactions did not play a role in the experiments here.

\subsection{Model calculations}

The Master Chemical Mechanism (MCM) in its latest version 3.3.1 was applied as base model for box model calcula- tions (MCM, 2017; Jenkin et al., 1997; Saunders et al., 2003). FACSIMILE was used as solver for differential equations in the model calculations.

In order to account for chamber effects, the following modifications were added to the MCM model. Dilution to all trace gases was applied. The dilution rate was calculated from the monitored replenishment flow rate that was consistent with the dilution of the $\mathrm{CO}_{2}$ tracer. Small chamber sources of formaldehyde and acetone were parameterized based on reference experiments as described in Rohrer et al. (2005), Karl et al. (2006), and Kaminski et al. (2017).

Temperature, pressure, $\mathrm{H}_{2} \mathrm{O}, \mathrm{NO}, \mathrm{NO}_{2}, \mathrm{HONO}$, and $\mathrm{O}_{3}$ concentrations were constrained to measured values. These constraints were used because chamber NO sources cannot be modeled accurately and could therefore lead to wrong conclusions in the analysis of turnover rates of radicals.

Photolysis frequencies, which were not measured, were calculated for clear sky conditions by the parameterization included in the MCM. They were scaled to take cloud cover and the transmission of the Teflon film into account by the ratio of measured to modeled photolysis frequency of $\mathrm{NO}_{2}$. This also applies for the photolysis frequency of pinonaldehyde in the base model case (MCM). All other model runs used the experimentally derived pinonaldehyde photolysis frequency (see Sect. 4.1).

The injection of pinonaldehyde was modeled as a source only present during the time period of injection to match the pinonaldehyde increase as measured by PTR-TOF-MS.

In a sensitivity study, the pinonaldehyde oxidation scheme developed by Fantechi et al. (2002) was implemented. In this mechanism, additional reaction pathways of the pinonaldehyde reaction with $\mathrm{OH}$ that are not included in the MCM are suggested. Only the four reaction pathways with significant yields $(>5 \%)$ were implemented for the sensitivity model run (Fig. 1). In addition, the fate of the most abundant $\mathrm{RO}_{2}$ formed from the reaction of pinonaldehyde with $\mathrm{OH}$ or photolysis is different in this model compared to the MCM mechanism (see above). Reaction rate constants and branching ratios were used as described in Fantechi et al. (2002). Simple rate coefficients such as $\operatorname{KDEC}\left(=1 \times 10^{6}\right)$ and KRO2NO $\left(=2.7 \times 10^{-12} \exp (360 / \mathrm{T})\right)$ from the MCM were used, when no specific reaction rate constants were mentioned. To account for possible $\mathrm{RO}_{2}+\mathrm{HO}_{2}$ reactions, a reaction scheme based on the reaction $\mathrm{C} 97 \mathrm{O} 2+\mathrm{HO}_{2}$ was added for all newly introduced $\mathrm{RO}_{2}$ species not included in the MCM. $\mathrm{RO}_{2}+\mathrm{HO}_{2}$ reactions form a corresponding hydroxyperoxide $(\mathrm{ROOH})$ that can either react with $\mathrm{OH}$ to regenerate the $\mathrm{RO}_{2}$ or photolyze to form the corresponding alkoxy radical (RO). Modifications by Fantechi et al. (2002) describe the chemistry from the $\mathrm{OH}$ attack on pinonaldehyde until the formation of stable products 4-hydroxynorpinonaldehyde, norpinonaldehyde, $\mathrm{CO} 23 \mathrm{C} 4 \mathrm{CHO}$, and $\mathrm{C} 818 \mathrm{CO}$. The chemistry of the products norpinonaldehyde, $\mathrm{CO} 23 \mathrm{C} 4 \mathrm{CHO}$, and $\mathrm{C} 818 \mathrm{CO}$ was treated as described in the MCM. For 4- 
Table 2. Overview of different model calculations.

\begin{tabular}{|c|c|c|c|}
\hline Model run & Model & $j_{\text {pinonaldehyde }}$ & $\mathrm{HO}_{2}$ \\
\hline MCM & $\mathrm{MCM}^{\mathrm{a}}$ & $\mathrm{MCM}^{\mathrm{b}}$ & calculated \\
\hline MCM_a & $\mathrm{MCM}^{\mathrm{a}}$ & $\exp ^{\mathrm{c}}$ & calculated \\
\hline MCM_b & $\mathrm{MCM}^{\mathrm{a}}$ & exp. ${ }^{c}$ & constrained \\
\hline FAN_a & Fantechi et al. $^{\mathrm{d}}$ & exp. ${ }^{c}$ & calculated \\
\hline FAN_b & Fantechi et al. ${ }^{\mathrm{d}}$ & exp. ${ }^{c}$ & constrained \\
\hline S1 & \multicolumn{3}{|c|}{$\begin{array}{l}\text { like FAN_a, with additional } \mathrm{RO}_{2} \rightarrow \mathrm{HO}_{2}\left(0.1 \mathrm{~s}^{-1}\right) \\
\text { for } \mathrm{RO}_{2}=\mathrm{C} 96 \mathrm{CO} 3, \mathrm{FAN} \text { D1, PINALO2, and FAN_G1 }\end{array}$} \\
\hline S1_mod & \multicolumn{3}{|c|}{$\begin{array}{l}\text { like FAN_a, with additional } \mathrm{RO}_{2} \rightarrow \mathrm{HO}_{2}\left(0.1 \mathrm{~s}^{-1}\right) \\
\text { for } \mathrm{RO}_{2}=\text { FAN_D1, PINALO2, and FAN_G1 }\end{array}$} \\
\hline S1_mod_hv & \multicolumn{3}{|c|}{$\begin{array}{l}\text { like } \mathrm{FAN} \text { a, with additional } \mathrm{RO}_{2} \rightarrow \mathrm{RO}_{2} \text { isom }\left(0.1 \mathrm{~s}^{-1}\right) \\
\text { for } \mathrm{RO}_{2}=\mathrm{FAN} \text {-D1, PINALO2, and FAN_G1 } \\
\text { followed by } \mathrm{RO}_{2} \text { isom }+h v \rightarrow \mathrm{HO}_{2}\left(j_{\text {glyoxal }}\right) \\
\text { and } \mathrm{RO}_{2} \text { isom }+\mathrm{NO} \rightarrow \mathrm{HO}_{2}+\mathrm{NO}_{2}\left(\mathrm{KRO}_{2} \mathrm{NO}^{\mathrm{a}}\right)\end{array}$} \\
\hline S2 & \multicolumn{3}{|c|}{$\begin{array}{l}\text { like FAN_a, with additional photolysis }\left(0.2 \times j_{\mathrm{NO} 2}\right) \\
\text { of first-generation pinonaldehyde products } \\
\text { (4-hydroxynorpinonaldehyde, NORPINAL, } \\
\text { CO13C4CHO, CO23C4CHO, C818CO) }\end{array}$} \\
\hline S3 & \multicolumn{3}{|c|}{$\begin{array}{l}\text { like FAN_a, with subsequent degradation of } \\
\text { 4-hydroxynorpinonaldehyde }\end{array}$} \\
\hline $2 \times \mathrm{KRO} 2 \mathrm{NO}$ & \multicolumn{3}{|c|}{$\begin{array}{l}\text { like FAN_a, with an enhanced reaction rate } \\
\text { of } 2 \times \mathrm{KRO} 2 \mathrm{NO}^{\mathrm{a}} \text { for all } \mathrm{RO}_{2}+\mathrm{NO} \text { reactions }\end{array}$} \\
\hline
\end{tabular}

\footnotetext{
${ }^{a}$ Master Chemical Mechanism v3.3.1. ${ }^{\mathrm{b}}$ Parametrization used by MCM v3.3.1. ${ }^{\mathrm{c}}$ Calculated from the measured solar actinic spectrum, using the absorption spectrum by Hallquist et al. (1997) and an estimated effective quantum yield of 0.9. d Mechanism by Fantechi et al. (2002) replaces pinonaldehyde chemistry in MCM (see the Supplement).
}

hydroxynorpinonaldehyde, no follow-up chemistry was considered.

Both the MCM and Fantechi et al. (2002) mechanism were tested under different conditions. An overview of used model calculations is given in Table 2 .

\section{Results}

Figures 2 and 3 show the concentration time series of pinonaldehyde and other measured trace gases together with MCM model results for the two experiments with and without $\mathrm{OH}$ scavenger, respectively.

Weather conditions were similar for both experiment days. The temperature inside the chamber increased over the course of each experiment from 305 to $315 \mathrm{~K}$. The solar zenith angle at noon was $30^{\circ}$ and maximum measured pinonaldehyde photolysis frequencies were approximately $3.5 \times 10^{-5} \mathrm{~s}^{-1}$ in both experiments.

In both experiments, the measured pinonaldehyde decay was significantly faster than predicted by the model once the chamber roof was opened. The predicted pinonaldehyde consumption rate was slower by $50 \%$ and $25 \%$ in the pure photolysis case and in the $\mathrm{OH}$ oxidation case, respectively.
Potential wall loss of pinonaldehyde in the chamber was tested in separate experiments, in which pinonaldehyde was injected into the dark chamber. The loss of pinonaldehyde in this case is consistent with the dilution calculated from the replenishment flow.

The two measured major organic products, acetone and formaldehyde, are also not well reproduced by the model calculations. In the experiment with the $\mathrm{OH}$ scavenger, in which pinonaldehyde is removed by photolysis only, the modeled concentrations of formaldehyde and acetone are $60 \%$ and $70 \%$ higher compared to the measurements, although the photolysis frequency of pinonaldehyde is obviously underestimated. In contrast, in the experiment in which pinonaldehyde was photolyzed and oxidized by $\mathrm{OH}$-modeled acetone concentrations are underestimated by $17 \%$ compared to measurements. Modeled formaldehyde concentrations are $6 \%$ smaller than measurements, which is within the measurement uncertainty. The smaller modeled acetone yield cannot be explained by the lower consumption of pinonaldehyde in the model alone. A sensitivity run that reproduces the pinonaldehyde consumption also underestimates the acetone concentrations. 

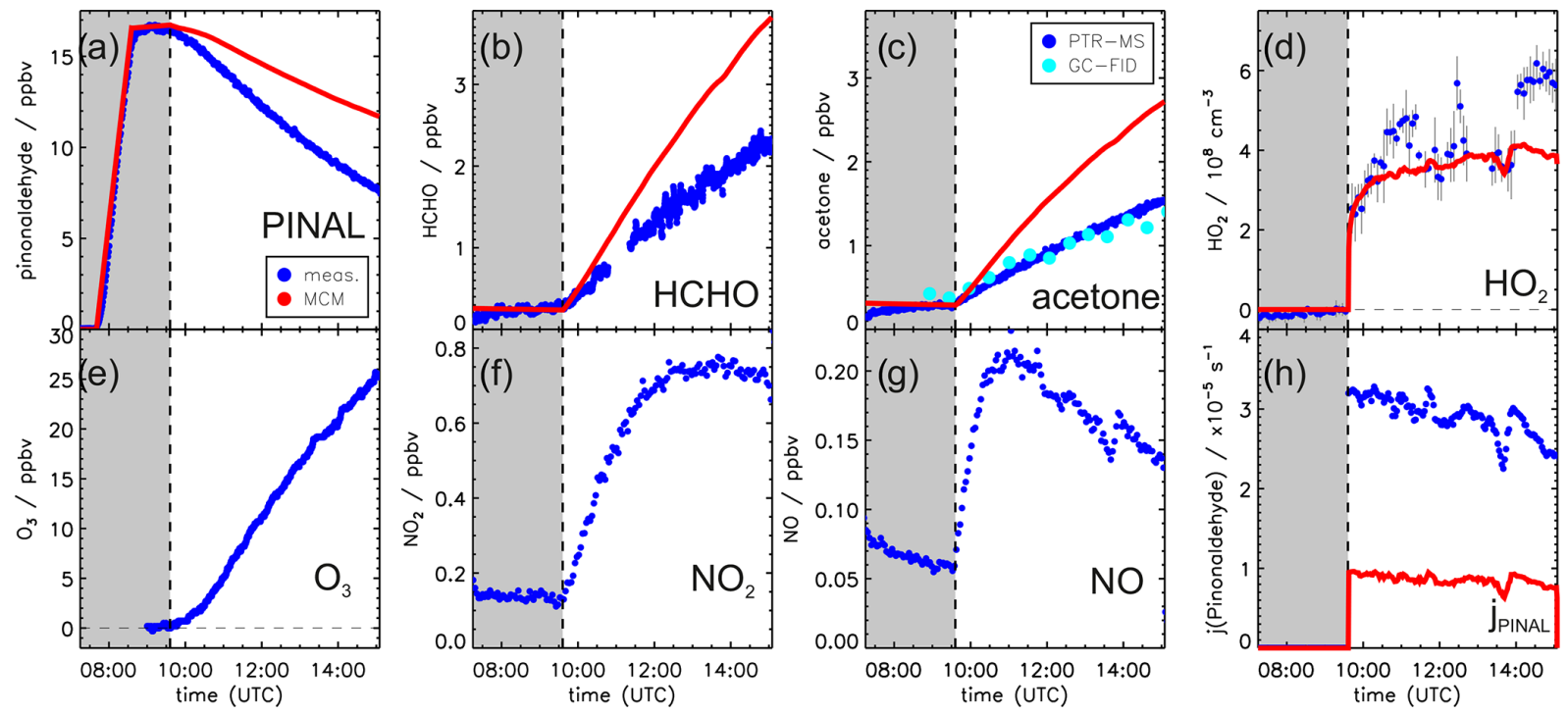

Figure 2. Measured and modeled trace gas concentrations and photolysis frequencies during photooxidation of pinonaldehyde in the presence of an $\mathrm{OH}$ scavenger. Pinonaldehyde is removed by photolysis only. Measured $\mathrm{O}_{3}, \mathrm{NO}_{2}$ and $\mathrm{NO}$ were used as constraints for the model. See the text for details of the pinonaldehyde photolysis frequency $(h)$. Grey-shaded areas indicate times when the chamber roof was closed.
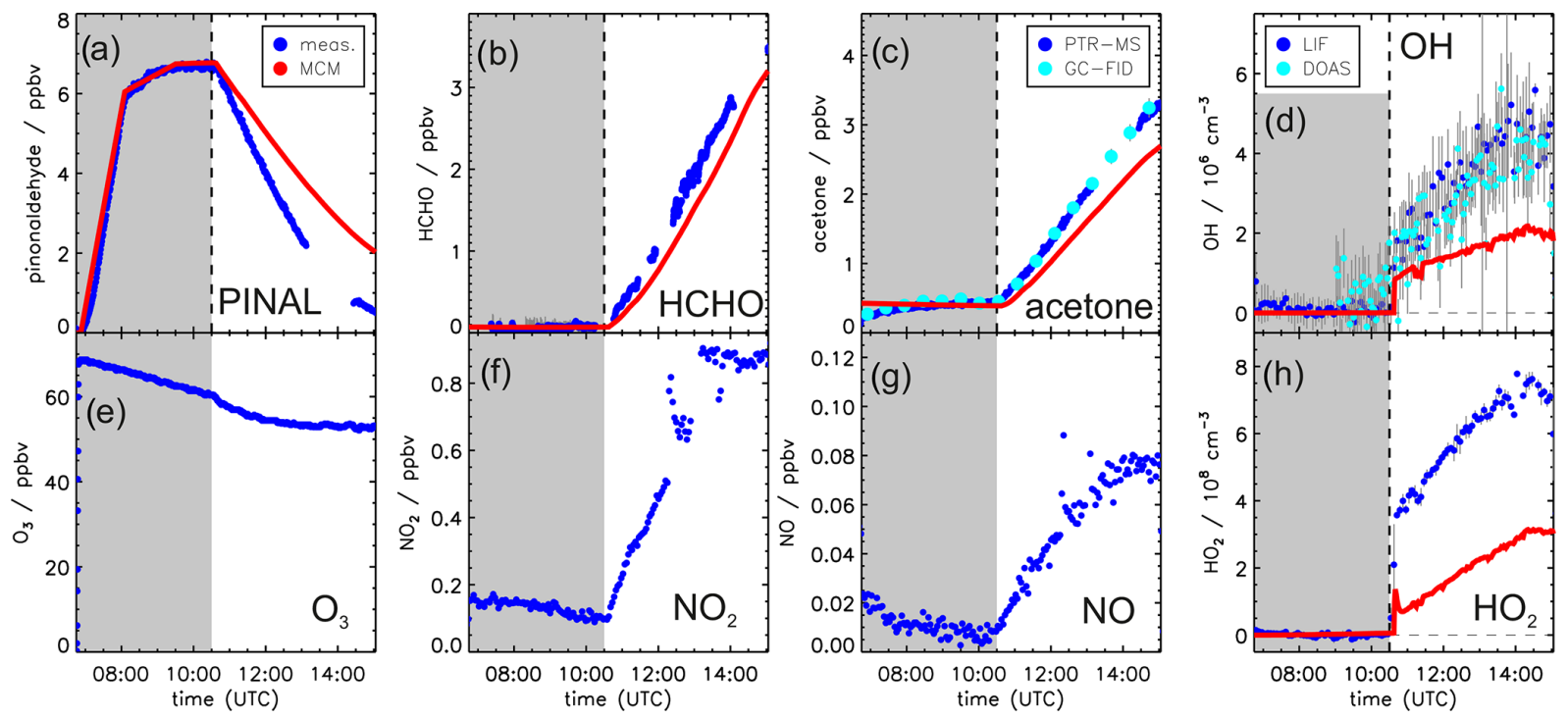

Figure 3. Measured and modeled trace gas concentrations during the photooxidation of pinonaldehyde without OH scavenger. In this experiment, pinonaldehyde is removed by photolysis and reaction with $\mathrm{OH}$. Measured $\mathrm{O}_{3}, \mathrm{NO}_{2}$, and $\mathrm{NO}$ were used as constraints for the model. Grey-shaded areas indicate times when the chamber roof was closed.

In the experiment without scavenger, $\mathrm{OH}$ and $\mathrm{HO}_{2}$ are both considerably underpredicted by the MCM. While $\mathrm{OH}$ shows an increasing discrepancy of up to a factor of 2 , modeled $\mathrm{HO}_{2}$ is a factor of 2-4 lower than measured. In the experiment with $\mathrm{OH}$ scavenger, measured and modeled $\mathrm{HO}_{2}$ concentrations agree within the stated uncertainty during the first part of the experiment, but the model underestimates the $\mathrm{HO}_{2}$ by $50 \%$ in the last hour.

Measured time series of acetone and formaldehyde are used to determine the total yields of acetone and formalde- hyde from the pinonaldehyde oxidation following the procedure described by Galloway et al. (2011), Kaminski et al. (2017), and Rolletter et al. (2019). In this approach, the measured time series of trace gases are corrected for loss and production that are not directly related to the chemical oxidation scheme of pinonaldehyde. This includes dilution of trace gases in the chamber, loss of formaldehyde due to photolysis, and a small production of formaldehyde and acetone in the sunlit chamber that is independent of the pinonaldehyde chemistry. If $\mathrm{OH}$ is also present, additional corrections 


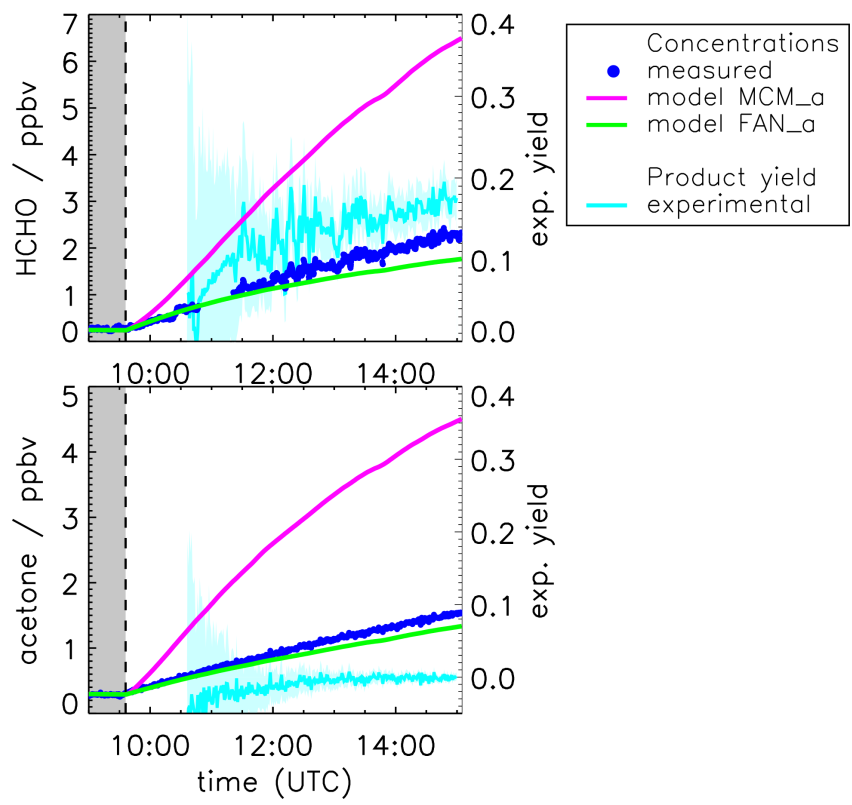

Figure 4. Measured and modeled formaldehyde and acetone mixing ratios for the experiment with $\mathrm{OH}$ scavenger. All model runs were done with measured photolysis frequencies for pinonaldehyde (see Fig. 6). Model runs include the MCM and the MCM with additions described in Fantechi et al. (2002). In addition, yields calculated from measured time series are shown (see text for details) with the $1 \sigma$ error derived from measurements and errors of the applied correction. Colored areas give the uncertainty of this calculation. The additional error caused by the uncertainty of the chamber source is not included here.

for the losses of formaldehyde and acetone due to their reactions with $\mathrm{OH}$ are applied. The corrected time series can then be used to calculate the ratio of a formed organic product and the consumed pinonaldehyde to derive the yield of the organic compound that is connected to the chemical degradation of pinonaldehyde. The main uncertainty in the calculated yields is caused by the uncertainty of the strength of the small chamber sources, which has to be taken from characterization experiments that were performed before and after the experiments with pinonaldehyde. Sensitivity studies in which the source strengths are systematically varied show that $1 \sigma$ uncertainties of yields are 0.2 and 0.1 for formaldehyde and acetone, respectively.

Figure 4 shows the result of the yield calculations. The formaldehyde yield is $(0.1 \pm 0.2)$ in the beginning and increases to approximately $(0.18 \pm 0.2)$ at the end of the experiment. The acetone yield of the photolysis is zero within the uncertainty of 0.1 .

The yields of acetone and formaldehyde are also calculated from the measured time series in the experiment when pinonaldehyde was oxidized by $\mathrm{OH}$ as described for the experiment with $\mathrm{OH}$ scavenger. Results are shown in Fig. 5. The yields of both species increase over the course of the experiment. The formaldehyde yield increases from approx-

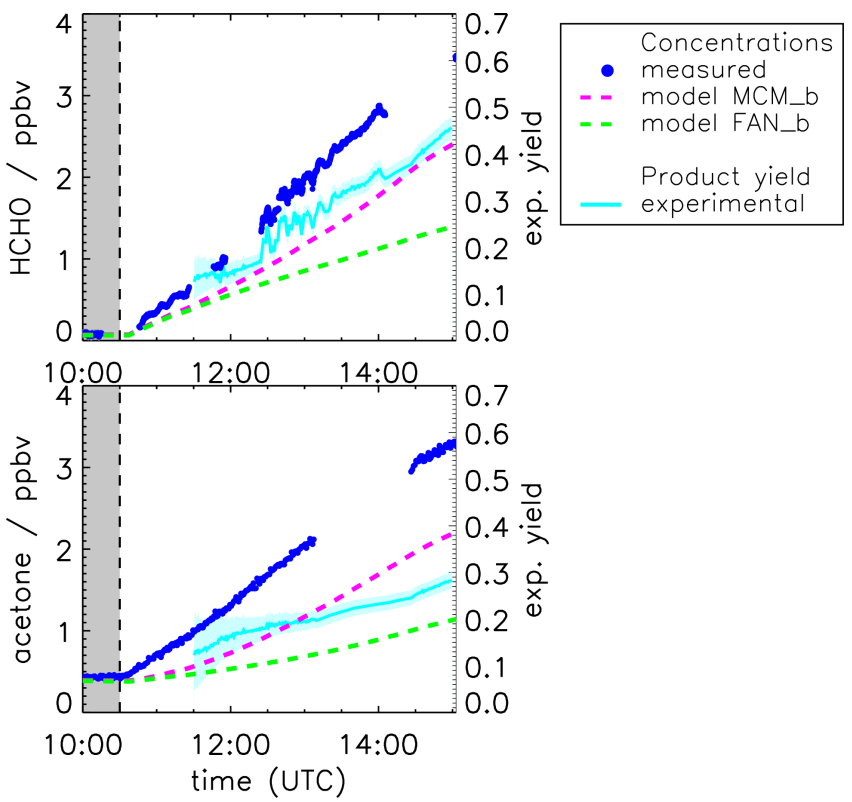

Figure 5. Measured and modeled formaldehyde and acetone mixing ratios for the experiment without $\mathrm{OH}$ scavenger. All model runs were done with measured photolysis frequencies for pinonaldehyde and with $\mathrm{HO}_{2}$ constrained to measurements (see Fig. 7). Model runs were done using the MCM and the MCM with modifications described in Fantechi et al. (2002). In addition, yields calculated from measured time series are shown (see text for details) with the $1 \sigma$ error derived from measurements and errors of the applied correction. Colored areas give the uncertainty of this calculation. The additional error caused by the uncertainty of the chamber source is not included here.

imately $(0.15 \pm 0.2)$ to values higher than $(0.45 \pm 0.2)$, and the acetone yield increases from approximately $(0.2 \pm 0.1)$ to $(0.3 \pm 0.1)$.

\section{Discussion}

\subsection{Pinonaldehyde photolysis}

In the presence of an $\mathrm{OH}$ scavenger, the pinonaldehyde decay observed in the chamber could be due to photolysis, wall loss, and dilution. As was shown by additional experiments in the dark chamber, wall loss is negligible on the timescale of a few hours. The effect of dilution was quantified from the measured dilution flow rate and the chamber volume and agreed with the results from the tracer $\left(\mathrm{CO}_{2}\right)$ measurements within $3 \%$. Without $\mathrm{OH}$, the chemical degradation of pinonaldehyde depends only on the photolysis frequency of pinonaldehyde. In MCM, photolysis frequencies are generally calculated as a function of solar zenith angle $\chi$ using three parameters $l, m$, and $n$.

$J=l \cdot(\cos (\chi))^{m} \cdot e^{(-n \cdot \sec (\chi))}$ 


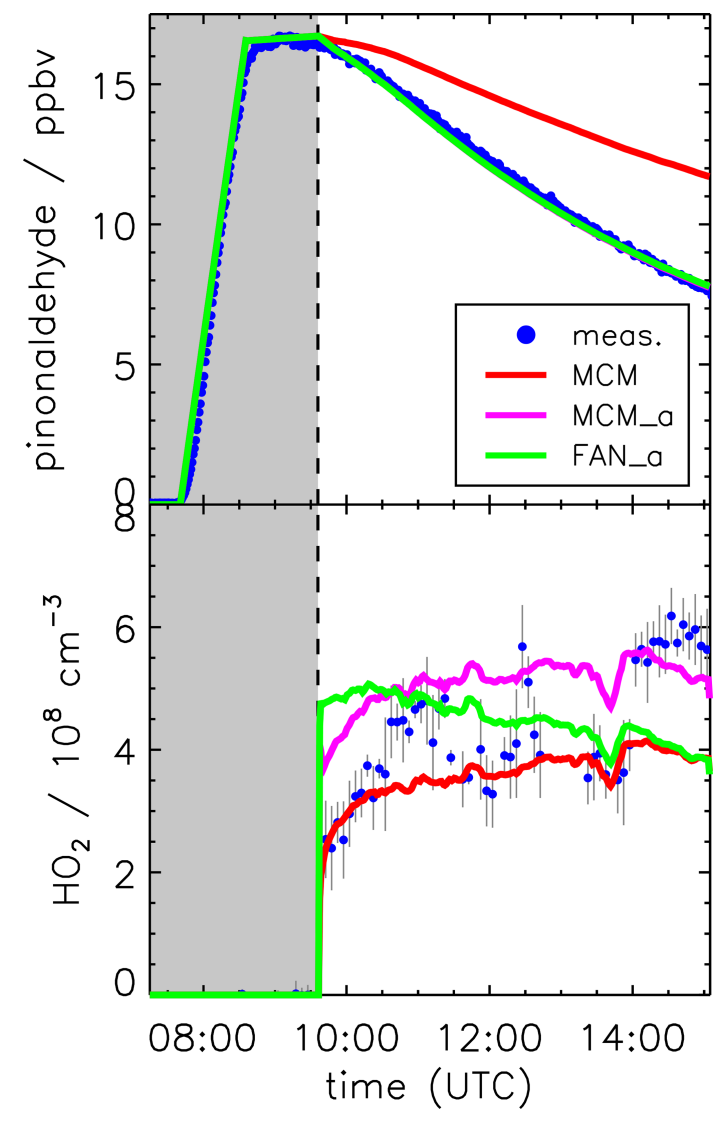

Figure 6. Pinonaldehyde and $\mathrm{HO}_{2}$ time series during the experiment with $\mathrm{OH}$ scavenger. Model runs were done either using the MCM with parameterization of pinonaldehyde photolysis frequencies (MCM), with measured values for photolysis frequencies (MCM_a; see the text for details), or with modifications described in Fantechi et al. (2002) (FAN_a). The pinonaldehyde concentration time profile is the same for both model runs MCM_a and FAN_a. Grey-shaded areas indicate times when the chamber roof was closed.

For pinonaldehyde, MCM is using the parameters $\left(l=2.792 \times 10^{-5} \mathrm{~s}^{-1}, \quad m=0.805, \quad n=0.338 ; \quad\right.$ valid for clear sky conditions) for the photolysis of n-butanal. The parameterization is based on the absorption spectrum measured for n-butanal at $298 \mathrm{~K}$ by Martinez et al. (1992) and the

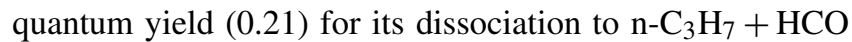
at $298 \mathrm{~K}$ and $1 \mathrm{~atm}$ by Tadić et al. (2001). For the evaluation of the chamber experiments, the clear sky values from the parameterization (Eq. 1) are corrected for the influence of cloud cover and chamber transmission by multiplying the clear sky value by the ratio of the measured to parameterized photolysis frequency of $\mathrm{NO}_{2}$. Following this procedure, the simulated decay of pinonaldehyde in the base model (MCM) is considerably slower than the observed decay (Fig. 6).

As an alternative, the photolysis frequency of pinonaldehyde is calculated using the measured spectrally resolved solar actinic flux (Sect. 2.2) and the pinonaldehyde absorption spectrum (280-340 nm) measured at $300 \mathrm{~K}$ by Hallquist et al. (1997). Good agreement between the observed and simulated (MCM_a) pinonaldehyde decay is achieved if an effective quantum yield of 0.9 is assumed (Fig. 6, upper panel). Here, the mean decay rate of pinonaldehyde between 10:00 and 15:00 UTC is $3.9 \times 10^{-5} \mathrm{~s}^{-1}$, of which $2.9 \times 10^{-5} \mathrm{~s}^{-1}$ is caused by photolysis and $1.0 \times 10^{-5} \mathrm{~s}^{-1}$ by dilution. The experimentally derived photolysis frequencies are approximately a factor of 3 to 3.5 higher than the values from the parameterization in the MCM. The experimental error $(20 \%)$ of the effective quantum yield (0.9) is mainly determined by the uncertainties of the absorption spectrum $(<5 \%$; Hallquist et al., 1997) and the actinic flux measurement (10\%). Error contributions from wall loss and dilution are small $(<5 \%)$.

The applied absorption cross sections by Hallquist et al. (1997) are the only published measurements and are recommended by IUPAC (Atkinson et al., 2006). The effective, wavelength-independent quantum yield determined in this work is significantly higher than in two other chamber studies, which report values of $0.14 \pm 0.03$ (Moortgat et al., 2002) and 0.4 (Jaoui and Kamens, 2003) for photolysis with natural sunlight. No recommendation for the quantum yield is given by IUPAC (Atkinson et al., 2006). Both chamber studies applied the absorption spectrum from Hallquist et al. (1997) for the calculation of photolysis frequencies. Jaoui and Kamens (2003) measured the solar radiation by a UV Eppley radiometer. The broadband instrument measures the spectrally integrated solar irradiance (spatially cosine-weighted photon flux density) from 300 to $400 \mathrm{~nm}$. The nontrivial conversion to a actinic flux spectrum (spatially isotropically weighted photon-flux density) between 300 and $340 \mathrm{~nm}$ needed for the evaluation of the pinonaldehyde photolysis frequencies has not been documented by the authors. The conversion requires knowledge of the spatial distribution of the incident solar radiation, which is a function of solar zenith angle, wavelength, atmospheric aerosol, and clouds (Hofzumahaus, 2006). Furthermore, the wavelength range of pinonaldehyde photolysis $(<340 \mathrm{~nm})$ strongly depends on the total atmospheric ozone column, while UV Eppley measurements (300-400 nm) are only weakly dependent on total ozone. Considerable errors may therefore be connected to the conversion of Eppley data to photolysis frequencies for pinonaldehyde.

In the study by Moortgat et al. (2002), solar actinic flux was directly measured by a spectroradiometer with good accuracy like in the present work. However, similar to Jaoui and Kamens (2003), Moortgat et al. (2002) had to apply large corrections for wall losses and dilution, each of which were of the same magnitude as the photolysis rate. The large difference by a factor of 7 in comparison to the present work is likely not explained by systematic errors of the correction.

The pinonaldehyde photolysis is faster than n-butanal because of its two carbonyl functions. This might be valid for other bi-carbonyl compounds that have non-conjugated car- 
bonyl functions, so that the use of the n-butanal photolysis frequency could systematically underestimate the photolysis frequencies of these compounds. However, the high quantum yield close to unity could also be a specific property of pinonaldehyde that might not apply for the photolysis of other bicarbonyl species.

Figure 4 shows the time series of measured acetone and formaldehyde concentrations together with results from model calculations applying the MCM. In contrast to the base case model (MCM, Fig. 2), measured photolysis frequencies are used (MCM_a). As a consequence of the higher photolysis frequencies, the consumption of pinonaldehyde leads to even larger productions of formaldehyde and acetone (approximately three times higher than measured values) compared to the base case model.

For conditions of this experiment, $80 \%$ of $\mathrm{RO}_{2}$ radicals formed in the photolysis reaction of pinonaldehyde are reacting with $\mathrm{NO}$ and only $20 \%$ are reacting with $\mathrm{HO}_{2}$, so that carbonyl compounds are expected to be the main organic products (Fig. 1). Acetone measured in this experiment is solely formed by the chamber source. Initial acetone yield values are negative because of the high uncertainty in the corrections that are applied in the yield calculation. In the beginning of an experiment, only small amounts of products are formed, which leads to a large uncertainty, so that negative values are not significant. It has to be stressed here again that the parametrization of the chamber source is the main uncertainty in the yield calculation. If the chamber source was overestimated, the constant measured acetone yield could also include a small contribution from the pinonaldehyde photolysis.

In a sensitivity model run (FAN_a), the pinonaldehyde oxidation scheme suggested by Fantechi et al. (2002) is tested for the experiment with $\mathrm{OH}$ scavenger. While the initial photodissociation step and the reaction of $\mathrm{C} 96 \mathrm{O} 2$ with $\mathrm{NO}$ are the same, the following decomposition of $\mathrm{C} 96 \mathrm{O}$ yields considerably different organic products. No acetone and less formaldehyde are produced together with mainly 4hydroxynorpinonaldehyde and norpinonaldehyde that were not measured in these experiments. Agreement between modeled and measured acetone is achieved within the accuracy of measurements of $10 \%$. Modeled formaldehyde concentrations are also only $20 \%$ lower than measured values. Thus, the model description of acetone and formaldehyde products is greatly improved by the use of the Fantechi et al. (2002) mechanism compared to the MCM.

To our knowledge, there is only one other study by Jaoui and Kamens (2003), which investigated the product yields of pinonaldehyde photolysis. Products were measured by gas chromatography in that chamber study in the presence and absence of an $\mathrm{OH}$ scavenger. The measured norpinonaldehyde yield agrees within the stated uncertainty with the yield proposed by Fantechi et al. (2002). Formaldehyde and acetone yields were not measured by Jaoui and Kamens (2003).
Using the MCM with the measured photolysis frequency (MCM_a) leads to an increase in modeled $\mathrm{HO}_{2}$ of about $25 \%$ (Fig. 6, lower panel), which can be explained by the higher amount of consumed pinonaldehyde that is formed at the end of the radical reaction chain together with 3,4-dioxopentanal ( $\mathrm{CO} 23 \mathrm{C} 4 \mathrm{CHO})$. Unfortunately, between 11:30 and 14:00 UTC experimental problems occurred in the $\mathrm{HO}_{2}$ measurements. Neither NO measurements nor photolysis frequencies showed any features that could explain the decrease in the $\mathrm{HO}_{2}$ concentration. The exact reason for the $\mathrm{HO}_{2}$ variations remains unclear and the uncertainty of $\mathrm{HO}_{2}$ measurements is likely higher $(50 \%)$ for this period. Implementing the modifications by Fantechi et al. (2002) results in a $\mathrm{HO}_{2}$ concentration time profile (FAN_a) that is different from both model runs done with the MCM mechanism. In the FAN_a model run $\mathrm{HO}_{2}$ is formed more rapidly compared to the MCM, and concentrations decrease towards the end of the experiment. The rate determining step in radical chain reactions is the reaction of $\mathrm{RO}_{2}$ with $\mathrm{NO}$ forming an alkoxy radical and $\mathrm{NO}_{2}$. In the $\mathrm{MCM}$, there are three $\mathrm{RO}_{2}+\mathrm{NO}$ reactions before the radical chain is terminated and the stable product $\mathrm{CO} 23 \mathrm{C} 4 \mathrm{CHO}$ is formed together with $\mathrm{HO}_{2}$. In contrast, in the Fantechi et al. (2002) mechanism only one $\mathrm{RO}_{2}+\mathrm{NO}$ reaction occurs before the stable products are formed and $\mathrm{HO}_{2}$ is regenerated. In addition, no subsequent chemistry of the formed product 4hydroxynorpinonaldehyde is included in the model, which would produce additional $\mathrm{HO}_{2}$, especially in later stages of the experiment.

\subsection{Photooxidation by $\mathrm{OH}$}

In the photooxidation experiment without $\mathrm{OH}$ scavenger (Fig. 3), a much faster decay of pinonaldehyde is observed compared to the case with $\mathrm{OH}$ scavenger (Fig. 2). Without scavenger, $30 \%$ of the decay in the beginning of the experiment is explained by photolysis and $5 \%$ by dilution. The remaining $65 \%$ are due to the removal of pinonaldehyde by $\mathrm{OH}$. However, $\mathrm{OH}$ concentrations rise over the course of the experiment and the pinonaldehyde fraction reacting with $\mathrm{OH}$ increase to up to $80 \%$. Here and in the following analysis, experimental photolysis frequencies are used, which assume a quantum yield of 0.9 (see Sect. 4.1). The photolysis and the $\mathrm{OH}$ reaction of pinonaldehyde lead to a mix of peroxy radicals (Fig. 1), which react mainly with $\mathrm{HO}_{2}$ or NO. During the experiment, the NO mixing ratio increases from about $10 \mathrm{pptv}$ to $80 \mathrm{pptv}$. Accordingly, the fraction of $\mathrm{RO}_{2}$ radicals reacting with $\mathrm{NO}$ increases from $20 \%$ to $55 \%$, while the $\mathrm{RO}_{2}$ fraction reacting with $\mathrm{HO}_{2}$ decreases.

Applying the experimental pinonaldehyde photolysis frequency to the model (MCM_a) improves the simulation of the pinonaldehyde decay compared to the base model run (MCM), which uses a slower parameterized photolysis frequency. However, even with the faster photolysis rate, the consumption of pinonaldehyde is underestimated (Fig. 7, up- 


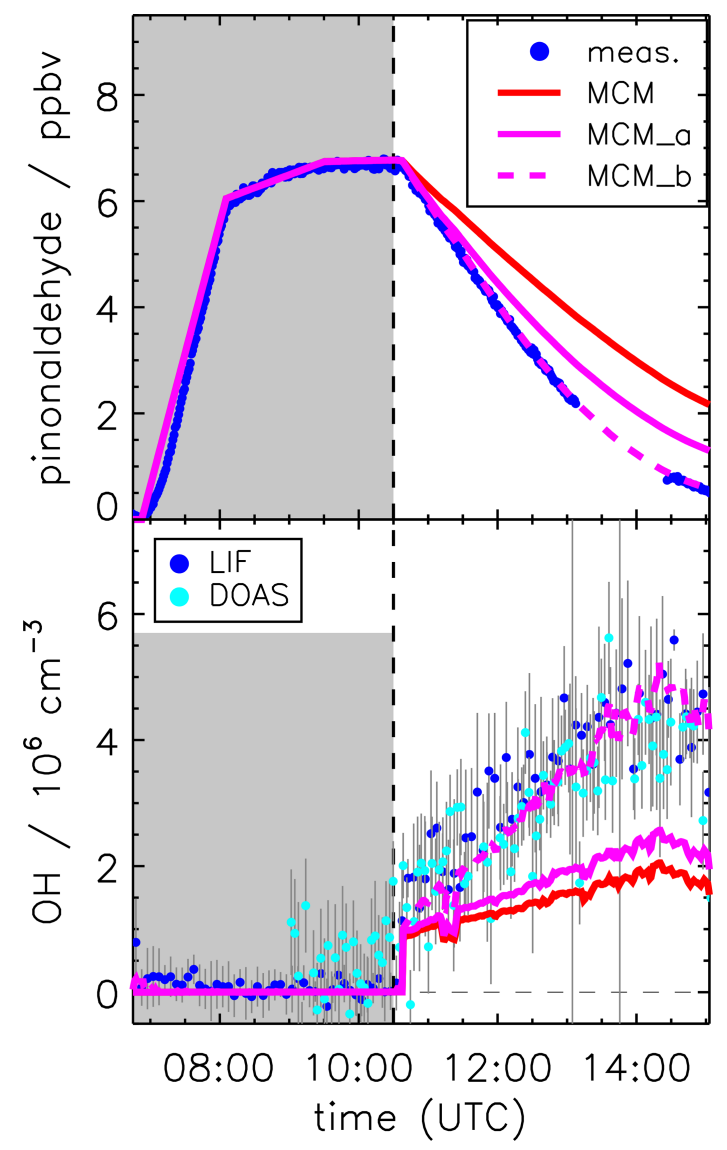

Figure 7. Pinonaldehyde and $\mathrm{OH}$ time series during the experiment without $\mathrm{OH}$ scavenger. Model runs were done either using the MCM with parameterization of pinonaldehyde photolysis frequencies (MCM) or with measured values for photolysis frequencies (MCM_a; see the text for details). The model MCM_b was additionally constrained to measured $\mathrm{HO}_{2}$ concentration, resulting in an agreement between modeled and measured (LIF and DOAS) $\mathrm{OH}$ concentrations. Grey-shaded areas indicate times when the chamber roof was closed.

per panel). At the end of the experiment (15:00 UTC), the remaining modeled pinonaldehyde concentration is a factor of 2 larger than the measured value. This is due to the lower $\mathrm{OH}$ concentration in the model compared to measurements. If modeled $\mathrm{OH}$ concentrations are increased to match measured values, which can be achieved by constraining $\mathrm{HO}_{2}$ in the model to measurements (MCM_b), modeled and measured pinonaldehyde concentrations agree within $10 \%$ (Fig. 7). This demonstrates that missing $\mathrm{OH}$ production in the model is most likely due to the underestimation of $\mathrm{HO}_{2}$, which forms $\mathrm{OH}$ by reaction with NO. This suggests that there is a $\mathrm{HO}_{2}$ source missing in the model. In a sensitivity run (not shown here) artificial $\mathrm{HO}_{2}$ sources were added to the model to quantify the required $\mathrm{HO}_{2}$ source strength. The missing $\mathrm{HO}_{2}$ source is increasing over the course of the experiment. A source strength between 0.8 and $1.5 \mathrm{ppbvh}^{-1}$ would be required to explain observations. The consumption of pinonaldehyde during the experiment is up to $2.5 \mathrm{ppbvh}^{-1}$, and thus a comparably large $\mathrm{HO}_{2}$ source would be required.

Implementation of the mechanism by Fantechi et al. (2002) does not improve the model-measurement agreement of $\mathrm{OH}$ and $\mathrm{HO}_{2}$ (Fig. 8) compared to the MCM. As discussed above, the mechanism by Fantechi et al. (2002) is able to describe $\mathrm{HO}_{2}$ concentrations as well as product formation of acetone and $\mathrm{HCHO}$, if pinonaldehyde is only consumed by photolysis. In contrast, reaction pathways that are connected to the reaction of pinonaldehyde $+\mathrm{OH}$ are not correctly described.

Modeled $\mathrm{HO}_{2}$ concentrations could be affected by the use of general reaction rate constants for reactions of $\mathrm{RO}_{2}$ with $\mathrm{HO}_{2}$ and $\mathrm{NO}(\mathrm{KRO} 2 \mathrm{HO} 2$ and $\mathrm{KRO} 2 \mathrm{NO})$, respectively. This might be an oversimplification for highly functionalized compounds. A sensitivity test (see the Supplement) with an enhanced reaction rate for $\mathrm{RO}_{2}+\mathrm{NO}$ reactions of $2 \times \mathrm{KRO} 2 \mathrm{NO}$ in the modified mechanism by Fantechi et al. (2002) was performed. As a result, the fraction of $\mathrm{RO}_{2}$ reacting with $\mathrm{NO}$ instead of $\mathrm{HO}_{2}$ is increased. This leads to an enhanced $\mathrm{HO}_{2}$ concentration of approximately $50 \%$ compared to the model run FAN_a. However, $\mathrm{HO}_{\mathrm{x}}$ concentrations are again underestimated compared to measurements, and the sensitivity run cannot reproduce the $\mathrm{HO}_{2}$ concentration time behavior from observations.

Besides reactions with $\mathrm{NO}$, new types of $\mathrm{RO}_{2}$ reactions have been recognized in the last decade that can produce $\mathrm{HO}_{x}$. These processes include unimolecular autoxidation reactions of $\mathrm{RO}_{2}$ (e.g., Crounse et al., 2013) and reactions of $\mathrm{RO}_{2}$ with $\mathrm{HO}_{2}$ yielding $\mathrm{OH}$ (e.g., Hasson et al., 2004). The new types of reactions become potentially important when NO concentrations are below 1 ppbv. These reactions are especially favored when the $\mathrm{RO}_{2}$ molecule contains functional groups, like carbonyl groups as in the case of pinonaldehyde peroxy radicals. For example, acetyl- and acetonyl- $\mathrm{RO}_{2}$ can react with $\mathrm{HO}_{2}$, forming alkoxy radicals and $\mathrm{OH}$ instead of terminating the radical reaction chain and forming hydroxyperoxides (Hasson et al., 2004; Dillon and Crowley, 2008). Other examples are reactions already included in the MCM, such as the photooxidation of methyl vinyl ketone (Praske et al., 2015; Fuchs et al., 2018). For pinonaldehyde, there have been no comparable reactions suggested so far, although pinonaldehyde and its degradation products have at least two carbonyl functions. Because $80 \%$ to $45 \%$ of $\mathrm{RO}_{2}$ reacts with $\mathrm{HO}_{2}$ for conditions of the experiment here, such reaction pathways have the potential to impact the $\mathrm{OH}$ production rate. A sensitivity test (not shown here) shows that $\mathrm{RO}_{2}+\mathrm{HO}_{2}$ reactions of $\mathrm{RO}_{2}$ included in the mechanism with a rate of $10 \times \mathrm{KRO} 2 \mathrm{HO} 2$ can reproduce measured $\mathrm{OH}$ concentrations. Nevertheless, the enhanced $\mathrm{HO}_{2}$ consumption increases the model-measurement discrepancy of $\mathrm{HO}_{2}$ even more.

Reported autoxidation reactions of $\mathrm{RO}_{2}$, which produce $\mathrm{HO}_{x}$ without NO, involve isomerization and decomposi- 

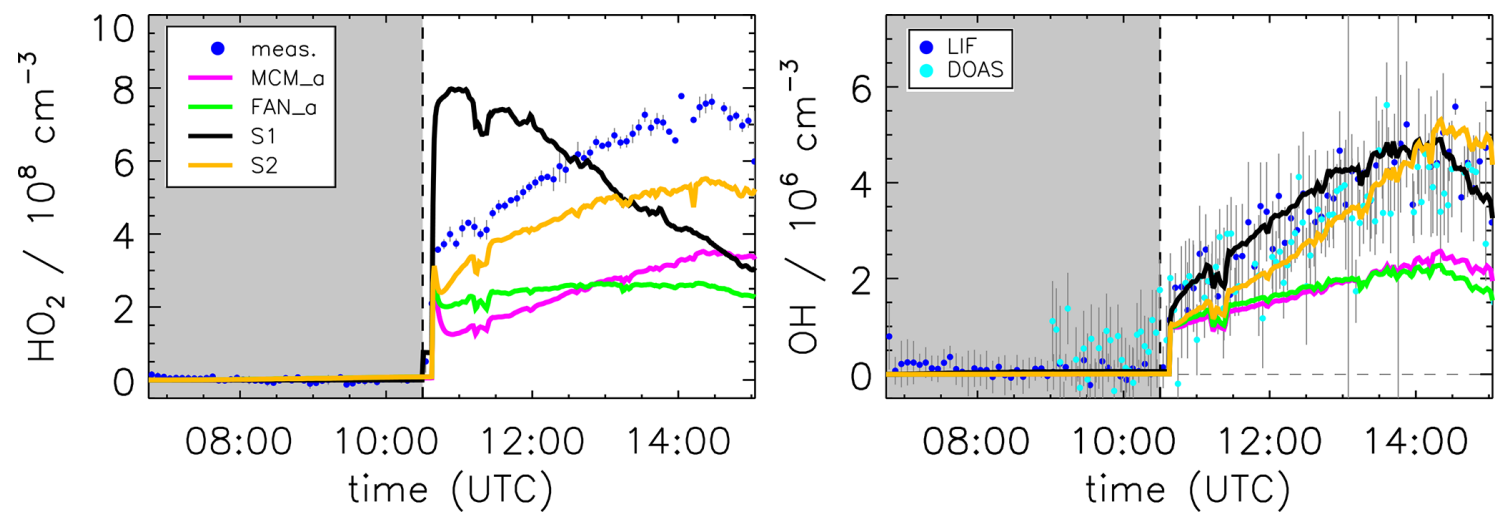

Figure 8. Model sensitivity study of the impact of potential additional $\mathrm{HO}_{2}$ formation by unimolecular $\mathrm{RO}_{2}$ reactions ( $\left.\mathrm{S} 1\right)$ or photolysis of pinonaldehyde oxidation products (S2) compared to the model base case (MCM_a) and the case using the mechanism by Fantechi et al. (2002) (FAN_a). See Table 2 for differences in the model runs. Grey-shaded areas indicate times when the chamber roof was closed.

tion of organic peroxy radicals. These reactions play a role, for example, in the photooxidation of isoprene (e.g., Fuchs et al., 2013; Peeters et al., 2014; Novelli et al., 2020) and methacrolein (Crounse et al., 2012; Fuchs et al., 2014), where $\mathrm{H}$-shift reactions in $\mathrm{RO}_{2}$ species lead to decomposition into a radical $\left(\mathrm{OH}\right.$ or $\left.\mathrm{HO}_{2}\right)$ and a carbonyl compound. In general, rate coefficients of $\mathrm{H}$-shift reactions are strongly enhanced by the presence of functional groups such as carbonyl groups, and can reach values on the order of $0.1 \mathrm{~s}^{-1}$ at room temperature (Crounse et al., 2013; Otkjær et al., 2018). Depending on the specific $\mathrm{RO}_{2}$ structure and its functional groups, either $\mathrm{OH}$ or $\mathrm{HO}_{2}$ can be formed. The presence of hydroxyl or hydroperoxy groups in carbonyl peroxy radicals, for example, favors the elimination of $\mathrm{HO}_{2}$.

In the chemical degradation of pinonaldehyde to its firstgeneration products (Fig. 1), a large number of multifunctional peroxy and alkoxy radicals are formed as intermediates. Thus, there is potential for additional $\mathrm{HO}_{2}$ formation by unimolecular reactions. This possibility is explored in a model sensitivity run for the four oxidation branches I-IV (Fantechi et al., 2002), which follow $\mathrm{OH}$ addition to pinonaldehyde. The model run S1 (see the Supplement) assumes that each of the initially formed peroxy radicals $(\mathrm{C} 96 \mathrm{CO} 3$, FAN_D1, PINALO2, and FAN_G1) is eventually converted to $\mathrm{HO}_{2}$ with a rate coefficient of $0.1 \mathrm{~s}^{-1}$. However, only FAN_D1, PINALO2, and FAN_G1 have an aldehyde group with a hydrogen that can be easily abstracted (see the Supplement). The model run (Fig. 8) shows a considerable enhancement of the $\mathrm{HO}_{2}$ concentration level in the first period of the experiment compared to model runs MCM_a and FAN_a, leading to good agreement between modeled and measured $\mathrm{OH}$. However, the temporal trend of the modeled $\mathrm{HO}_{2}$ is not well described. While the observed $\mathrm{HO}_{2}$ shows a steady increase from the beginning to the end of the experiment, the simulation S1 shows a continuous decrease that follows the concentration of the short-lived $\mathrm{RO}_{2}$ radicals. The opposite temporal trend suggests that additional $\mathrm{HO}_{2}$ formation by a fast process in the oxidation branches I-IV is not a likely explanation. It indicates that the additionally required $\mathrm{HO}_{2}$ is slowly built up, probably from stable products of the pinonaldehyde oxidation.

One such possibility would be the photolysis of firstgeneration products. This idea is tested in model run S2 (Table 2, Fig. 8). All products of the pinonaldehyde photooxidation have either two or three carbonyl groups and therefore are likely to undergo photolysis. $\mathrm{CO} 23 \mathrm{C} 4 \mathrm{CHO}$ and $\mathrm{C} 818 \mathrm{CO}$ even have conjugated carbonyl functions similar to glyoxal, which photolysis is up to 2 times faster than pinonaldehyde. However, using the photolysis frequency of glyoxal as an upper limit for the photolysis frequency of the products formed here, is not sufficient to significantly improve the $\mathrm{HO}_{2}$ model-measurement agreement. Only if a strongly enhanced photolysis frequency equivalent to $0.2 \times j_{\mathrm{NO} 2}$ is applied, does modeled $\mathrm{HO}_{2}$ comes close to the observed values. In this case, the temporal trend of the simulation is similar to the observed time behavior of $\mathrm{HO}_{2}$ and also $\mathrm{OH}$ is reasonably well reproduced. This supports the hypothesis that the additional $\mathrm{HO}_{2}$ is slowly formed from stable oxidation products. However, the value for the assumed photolysis frequency, which is 200 times larger than of pinonaldehyde, appears unrealistically high.

Another possibility is that the fast $\mathrm{H}$-shift isomerization of $\mathrm{RO}_{2}$ radicals (see the Supplement) leads to the formation of peroxy acids with additional carbonyl functions in high yields. As discussed above, these bi-functional compounds could photolyze faster than currently implemented in the mechanism. A sensitivity test (S1_mod_hv; see the Supplement) was performed that includes isomerization of $\mathrm{RO}_{2}$ with a - HCO group. Products are assumed to photolyze with a photolysis rate that is 2 times higher than that of glyoxal. Implementation of these reactions leads to $\mathrm{HO}_{2}$ concentrations that are increased by up to $60 \%$ compared to the sensitivity run that includes only isomerization reactions. Calculated $\mathrm{HO}_{2}$ concentrations underestimate measurements by 
factor of 2. The sensitivity test reproduces measured $\mathrm{OH}$ concentrations within the measurement uncertainty.

No subsequent chemistry of 4-hydroxynorpinonaldehyde is included in the mechanism so far. In the experiment here, 4-hydroxynorpinonaldehyde is formed with an overall yield of approximately $25 \%$. 4-hydroxynorpinonaldehyde is highly functionalized and $\mathrm{RO}_{2}$ radicals formed in its degradation could undergo fast isomerization reactions. For a sensitivity run (S3; see the Supplement) a mechanism was deduced with the structure-activity relationship (SAR; Kwok and Atkinson, 1995; Vereecken and Peeters, 2009; Vereecken and Nozière, 2020) method. However, the impact of the tested 4-hydroxynorpinonaldehyde degradation scheme on the $\mathrm{HO}_{2}$ formation was small $(\leq 10 \%)$ compared to the modified mechanism by Fantechi et al. (2002). Unfortunately, no measurements of stable oxidation products other than acetone and $\mathrm{HCHO}$ were available. Without further product measurements the whole analysis discussed here relies on product distribution prescribed by the models. Further experiments that measure oxidation products and yields could help to better constrain branching ratios in degradation mechanisms. In addition, theoretical studies could investigate subsequent degradation schemes of major products in more detail.

The continuous increase in the acetone and formaldehyde yields during the experiment (Fig. 5) indicates that both species are not only formed from the first reaction step of pinonaldehyde with $\mathrm{OH}$ but also from further oxidation of organic products.

The base model (Fig. 3, MCM) underestimates the pinonaldehyde consumption but shows a good modelmeasurement agreement with formaldehyde and acetone within the measurement uncertainty. In contrast, the model, which uses measured pinonaldehyde photolysis frequencies and is constrained to measured $\mathrm{HO}_{2}$, produces up to $30 \%$ less acetone and formaldehyde than measured (Fig. 5, MCM_b). The discrepancies increase quickly during the first $2 \mathrm{~h}$ of the experiment, when pinonaldehyde is the most important reaction partner for $\mathrm{OH}$, and slow down when oxidation products gain importance at later times of the experiment. The elevated $\mathrm{HO}_{2}$ concentrations change the product distribution compared to the base case with less formed formaldehyde and acetone because $\mathrm{RO}_{2}+\mathrm{HO}_{2}$ reactions producing hydroxyperoxides become more important compared to the $\mathrm{RO}_{2}+\mathrm{NO}$ pathway. In the chemical model, acetone and formaldehyde of this reaction pathway are formed by the slow photolysis ( 10 times slower than the photolysis of pinonaldehyde) of pinonic acid and perpinonic acid that are produced in the subsequent chemistry of hydroxyperoxides. Therefore, acetone and formaldehyde yields are smaller in the MCM model run, if $\mathrm{HO}_{2}$ concentrations are correctly described compared to the base case MCM model, when $\mathrm{HO}_{2}$ is significantly underestimated.

Implementation of the mechanism by Fantechi et al. (2002) with $\mathrm{HO}_{2}$ concentrations and pinonaldehyde photol- ysis frequency also constrained to measurements (FAN_b) makes the model-measurement agreement for acetone and formaldehyde worse. Acetone and formaldehyde yields are lowered and 4-hydroxynorpinonaldehyde and norpinonaldehyde are produced instead. Acetone and formaldehyde time series agree for the photolysis experiment, when the mechanism by Fantechi et al. (2002) is applied. Similarly, the majority of consumed pinonaldehyde (approximately $65 \%$ ) forms the peroxy radical $\mathrm{C} 96 \mathrm{O} 2$ either by photolysis or reaction pathway I (Fig. 1), when $\mathrm{OH}$ is also present. Therefore, it can be assumed that the $\mathrm{C} 96 \mathrm{O} 2+\mathrm{NO}$ reaction channel is not responsible for the underprediction of acetone and formaldehyde, at least for the early times of the experiments, when contributions from $\mathrm{OH}$ reactions of product species are small. However, because $\mathrm{RO}_{2}+\mathrm{HO}_{2}$ reactions are more important in the experiment with $\mathrm{OH}$ oxidation (see above), additional $\mathrm{HO}_{2}$ production from this reaction pathway has the potential to serve as an explanation for the observed discrepancies. In addition, minor pathways could produce additional formaldehyde and acetone to explain the modelmeasurement discrepancy right after the start of the pinonaldehyde oxidation. At later times of the experiment, additional production of acetone and formaldehyde from the further degradation of oxidation products need to be assumed to close the gap. For example, this could be due to a reaction channel of the alkoxy radical $\mathrm{R}^{\prime} \mathrm{O} 8$ that does not produce norpinonaldehyde but produces acetone and formaldehyde instead. However, the exact chemical mechanism that is responsible for the additional acetone and formaldehyde cannot be determined from measurements in these experiments.

Presently, there is only one work of Noziére et al. (1999) where acetone and formaldehyde were quantitatively measured for the reaction of pinonaldehyde with $\mathrm{OH}$. The formaldehyde yield was determined to be $1.52 \pm 0.56$, significantly higher than the yield measured in this work. The acetone yield in Noziére et al. (1999) lies with $0.15 \pm 0.07$ in the range of the acetone yield determined here for the times of the experiment when pinonaldehyde is the dominant $\mathrm{OH}$ reactant. In the oxidation scheme of pinonaldehyde, acetone and formaldehyde are typically formed together so that similar yields would be expected. The high $\mathrm{HCHO}$ yield measured by Noziére et al. (1999) can be partially explained by additional fast photolysis of pinonaldehyde and possibly other products by the $254 \mathrm{~nm}$ lamps used to generate $\mathrm{OH}$ by photodissociation of $\mathrm{H}_{2} \mathrm{O}_{2}$ (Fantechi et al., 2002).

\section{Summary and conclusions}

The photooxidation of pinonaldehyde was investigated under natural sunlight at low NO concentrations $(<0.2 \mathrm{ppbv})$ in the presence and absence of an $\mathrm{OH}$ scavenger. Two experiments were conducted with maximum pinonaldehyde concentrations of $16.5 \mathrm{ppbv}$ (with $\mathrm{OH}$ scavenger) and $6.5 \mathrm{ppbv}$ (without $\mathrm{OH}$ scavenger). Measured times series were com- 
pared to model calculations based on the recent version of the Master Chemical Mechanism (version 3.3.1).

Model results show that the pinonaldehyde consumption is underestimated in the experiment with $\mathrm{OH}$ scavenger. In contrast, the concentration of the measured products acetone and formaldehyde is overestimated by $60 \%$ and $70 \%$, respectively. The observed decay of pinonaldehyde requires a quantum yield of 0.9 for the photolysis reaction. Previous investigations of the quantum yield determined lower yields of 0.15 (Moortgat et al., 2002) and $\leq 0.4$ (Jaoui and Kamens, 2003). However, the solar actinic flux could not accurately be determined in these other chamber studies and large corrections for wall loss were applied. Calculations using the measured absorption spectrum (Hallquist et al., 1997) and a quantum yield of 0.9 give photolysis frequencies, which are a factor of 3.5 times higher than values calculated by the parameterization implemented in the MCM, and thus photolysis of pinonaldehyde is significantly underestimated if this parameterization is applied.

Similarly, the pinonaldehyde consumption is underestimated by the MCM model in the experiment, where the pinonaldehyde consumption is dominated by its reaction with $\mathrm{OH}$ radicals. Implementing the measured photolysis frequency improves model-measurement agreement. The remaining discrepancy is caused by underestimated $\mathrm{OH}$ radical concentrations leading to a slower pinonaldehyde consumption. Constraining $\mathrm{HO}_{2}$ model concentrations to the measurements brings $\mathrm{OH}$ concentrations in model and measurement into agreement. As a consequence, the pinonaldehyde concentration profile is also reproduced within the measurement uncertainty. The closed $\mathrm{OH}$ budget indicates that a $\mathrm{HO}_{2}$ source is missing in this mechanism. The additional $\mathrm{HO}_{2}$ source would be at least half the rate at which pinonaldehyde is consumed. $\mathrm{HO}_{2}$ would therefore need to be reproduced much faster than current chemical models suggest in one of the major oxidation pathways. Because a large fraction of $\mathrm{RO}_{2}$ radicals $(45 \%-80 \%)$ react with $\mathrm{HO}_{2}$, potential reaction pathways that do not lead to the formation of hydroxyperoxide but reform radicals have the potential to contribute the regeneration of $\mathrm{HO}_{2}$. If fast unimolecular $\mathrm{RO}_{2}$ reactions existed that could compete with $\mathrm{RO}_{2}+\mathrm{NO}$ and $\mathrm{RO}_{2}+\mathrm{HO}_{2}$ reactions, they could also add to additional $\mathrm{HO}_{2}$ production. Nevertheless, a fast degradation of first-generation product species forming $\mathrm{HO}_{2}$ shows a better agreement with measured $\mathrm{HO}_{2}$ concentration time profiles rather than reactions of $\mathrm{RO}_{2}$ species.

The yield of formaldehyde in the pinonaldehyde photolysis with $\mathrm{OH}$ scavenger present is determined to be $0.18 \pm 0.20$. No acetone formation is observed. Model calculations based on the MCM constrained with the measured photolysis frequency overestimate formaldehyde and acetone concentrations by a factor of approximately 3 . In the experiment with $\mathrm{OH}$ the yields of acetone and formaldehyde increase over the course of the experiment from $(0.2 \pm 0.1)$ to $(0.3 \pm 0.1)$ and from $(0.15 \pm 0.2)$ to $(0.45 \pm 0.2)$, respec- tively. The increasing yields indicate that both species are also formed by the subsequent chemistry of products formed in the first reaction steps.

Modifications of the degradation mechanism proposed by Fantechi et al. (2002), including a new product distribution and additional products for the initial attack of $\mathrm{OH}$, reproduce measured acetone and formaldehyde concentrations within their uncertainty as long as the reaction with $\mathrm{OH}$ is suppressed. In the experiment with $\mathrm{OH}$, the modelmeasurement agreement for both species decreases after implementing the modifications by Fantechi et al. (2002). This indicates that the pathways relevant when $\mathrm{OH}$ is dominating the fate of pinonaldehyde lack sources of acetone and formaldehyde in this case.

Field campaigns in environments dominated by monoterpene emissions like the Bio-hydro-atmosphere interactions of Energy, Aerosols, Carbon, H2O, Organics, and NitrogenRocky Mountain Organic Carbon Study (BEACHONROCS; Kim et al., 2013) or the Hyytiälä United Measurements of Photochemistry and Particles in Air - Comprehensive Organic Precursor Emission and Concentration study (HUMPPA-COPEC; Hens et al., 2014) showed that $\mathrm{OH}$ and $\mathrm{HO}_{2}$ radical concentrations were underestimated in model calculations by up to a factor of 2.5. Constraining modeled $\mathrm{HO}_{2}$ concentrations to measurements allowed for reproducing $\mathrm{OH}$ radical concentrations. In addition, chamber studies on the photooxidation of $\alpha$-pinene (Rolletter et al., 2019) and $\beta$-pinene (Kaminski et al., 2017) also confirmed that the current $\alpha$-pinene and $\beta$-pinene mechanisms lack $\mathrm{HO}_{2}$ sources. It is currently unknown if the missing source is part of reactions forming first-generation products or the subsequent chemistry of the degradation products. Here, it is shown that in the mechanism of the photooxidation of pinonaldehyde, a degradation product of $\alpha$-pinene, a $\mathrm{HO}_{2}$ source is also missing. However, the findings here cannot explain the discrepancies observed in the $\alpha$-pinene chamber experiments and field campaigns because the pinonaldehyde yield in the $\alpha$-pinene degradation is rather small (5\%, Rolletter et al. (2019)). Nevertheless, this result is an example for a second-generation species that produces significantly more $\mathrm{HO}_{2}$ than suggested in current chemical models. Further experiments will be required to investigate whether other oxidation products from the degradation of monoterpenes could also explain observations of missing $\mathrm{HO}_{2}$ sources.

Data availability. Data of the experiments in the SAPHIR chamber used in this work are available on the EUROCHAMP data homepage: https://doi.org/10.25326/G53K-WH75 (Fuchs et al., 2020a) and https://doi.org/10.25326/887C-F682 (Fuchs et al., 2020b).

Supplement. The supplement related to this article is available online at: https://doi.org/10.5194/acp-20-13701-2020-supplement. 
Author contributions. MR analyzed the data and wrote the paper. $\mathrm{HF}$ and MK designed the experiments. $\mathrm{HF}$ conducted the $\mathrm{HO}_{x}$ radical measurements. BB conducted the radiation measurements. MK and RW were responsible for the GC measurements. RT was responsible for the PTR-TOF-MS measurements. XL was responsible for the HONO measurements and H-PD for the DOAS OH data. FR was responsible for the $\mathrm{NO}_{x}$ and $\mathrm{O}_{3}$ data. All co-authors commented on the manuscript.

Competing interests. The authors declare that they have no conflict of interest.

Special issue statement. This article is part of the special issue "Simulation chambers as tools in atmospheric research (AMT/ACP/GMD inter-journal SI)". It is not associated with a conference.

Acknowledgements. This work was supported by the EU Horizon 2020 program Eurochamp2020 (grant agreement no. 730997). This project has received funding from the European Research Council (ERC) under the European Union's Horizon 2020 research and innovation programme (SARLEP grant agreement no. 681529). The authors thank Luc Vereecken for his help with the 4-hydroxynorpinonaldehyde mechanism.

Financial support. This research has been supported by the European Commission, H2020 Research Infrastructures (grant no. EUROCHAMP-2020 (730997)) and the European Commission, H2020 European Research Council (grant no. SARLEP (681529)).

The article processing charges for this open-access publication were covered by a Research Centre of the Helmholtz Association.

Review statement. This paper was edited by Jean-Francois Doussin and reviewed by William Carter and two anonymous referees.

\section{References}

Alves, C., Carvalho, A., and Pio, C.: Mass balance of organic carbon fractions in atmospheric aerosols, J. Geophys. Res.-Atmos., 107, ICC7-1-ICC7-9, https://doi.org/10.1029/2001jd000616, 2002.

Atkinson, R. and Arey, J.: Atmospheric degradation of volatile organic compounds, Chem. Rev., 103, 4605-4638, https://doi.org/10.1021/cr0206420, 2003.

Atkinson, R., Baulch, D. L., Cox, R. A., Crowley, J. N., Hampson, R. F., Hynes, R. G., Jenkin, M. E., Rossi, M. J., and Troe, J.: Evaluated kinetic and photochemical data for atmospheric chemistry: Volume $\mathrm{I}-$ gas phase reactions of $\mathrm{O}_{x}, \mathrm{HO}_{x}$, $\mathrm{NO}_{x}$ and $\mathrm{SO}_{x}$ species, Atmos. Chem. Phys., 4, 1461-1738, https://doi.org/10.5194/acp-4-1461-2004, 2004.
Atkinson, R., Baulch, D. L., Cox, R. A., Crowley, J. N., Hampson, R. F., Hynes, R. G., Jenkin, M. E., Rossi, M. J., Troe, J., and IUPAC Subcommittee: Evaluated kinetic and photochemical data for atmospheric chemistry: Volume II - gas phase reactions of organic species, Atmos. Chem. Phys., 6, 3625-4055, https://doi.org/10.5194/acp-6-3625-2006, 2006.

Bohn, B. and Zilken, H.: Model-aided radiometric determination of photolysis frequencies in a sunlit atmosphere simulation chamber, Atmos. Chem. Phys., 5, 191-206, https://doi.org/10.5194/acp-5-191-2005, 2005.

Bohn, B., Rohrer, F., Brauers, T., and Wahner, A.: Actinometric measurements of $\mathrm{NO}_{2}$ photolysis frequencies in the atmosphere simulation chamber SAPHIR, Atmos. Chem. Phys., 5, 493-503, https://doi.org/10.5194/acp-5-493-2005, 2005

Boy, M., Petäjä, T., Dal Maso, M., Rannik, Ü., Rinne, J., Aalto, P., Laaksonen, A., Vaattovaara, P., Joutsensaari, J., Hoffmann, T., Warnke, J., Apostolaki, M., Stephanou, E. G., Tsapakis, M., Kouvarakis, A., Pio, C., Carvalho, A., Römpp, A., Moortgat, G., Spirig, C., Guenther, A., Greenberg, J., Ciccioli, P., and Kulmala, M.: Overview of the field measurement campaign in Hyytiälä, August 2001 in the framework of the EU project OSOA, Atmos. Chem. Phys., 4, 657-678, https://doi.org/10.5194/acp-4657-2004, 2004.

Cahill, T. M., Seaman, V. Y., Charles, M. J., Holzinger, R., and Goldstein, A. H.: Secondary organic aerosols formed from oxidation of biogenic volatile organic compounds in the Sierra Nevada Mountains of California, J. Geophys. Res.-Atmos., 111, D16312, https://doi.org/10.1029/2006jd007178, 2006.

Calogirou, A., Larsen, B. R., and Kotzias, D.: Gas-phase terpene oxidation products: a review, Atmos. Environ., 33, 1423-1439, https://doi.org/10.1016/S1352-2310(98)00277-5, 1999.

Capouet, M., Peeters, J., Nozi'ere, B., and Müller, J.-F.: Alphapinene oxidation by $\mathrm{OH}$ : simulations of laboratory experiments, Atmos. Chem. Phys., 4, 2285-2311, https://doi.org/10.5194/acp4-2285-2004, 2004.

Crounse, J. D., Knap, H. C., Ornso, K. B., Jorgensen, S., Paulot, F., Kjaergaard, H. G., and Wennberg, P. O.: On the atmospheric fate of methacrolein: 1. Peroxy radical isomerization following addition of $\mathrm{OH}$ and $\mathrm{O}_{2}$, J. Phys. Chem. A, 116, 5756-5762, https://doi.org/10.1021/jp211560u, 2012.

Crounse, J. D., Nielsen, L. B., Jørgensen, S., Kjaergaard, H. G., and Wennberg, P. O.: Autoxidation of organic compounds in the atmosphere, J. Phys. Chem. Lett., 4, 3513-3520, https://doi.org/10.1021/jz4019207, 2013.

Dash, M. R. and Rajakumar, B.: Abstraction kinetics of $\mathrm{H}$-atom by $\mathrm{OH}$ radical from pinonaldehyde $\left(\mathrm{C}_{10} \mathrm{H}_{16} \mathrm{O}_{2}\right)$ : $\mathrm{Ab}$ initio and transition-state theory Calculations, J. Phys. Chem. A, 116, 5856-5866, https://doi.org/10.1021/jp209208e, 2012.

Daumont, D., Brion, J., Charbonnier, J., and Malicet, J.: Ozone UV spectroscopy I: Absorption cross-sections at room temperature, J. Atmos. Chem., 15, 145-155, https://doi.org/10.1007/bf00053756, 1992.

Dillon, T. J. and Crowley, J. N.: Direct detection of OH formation in the reactions of $\mathrm{HO}_{2}$ with $\mathrm{CH}_{3} \mathrm{C}(\mathrm{O}) \mathrm{O}_{2}$ and other substituted peroxy radicals, Atmos. Chem. Phys., 8, 4877-4889, https://doi.org/10.5194/acp-8-4877-2008, 2008.

Dorn, H.-P., Brandenburger, U., Brauers, T., and Hausmann, M.: A new in-situ laser long-path absorption instrument for the mea- 
surement of tropospheric OH radicals, J. Atmos. Sci., 52, 33733380, 1995a.

Dorn, H. P., Neuroth, R., and Hofzumahaus, A.: Investigation of $\mathrm{OH}$ absorption cross sections of rotational transitions in the $\mathrm{A}^{2} \Sigma^{+}, v^{\prime}=0 \leftarrow \mathrm{X}^{2} \Pi, v-0$ band under atmospheric conditions: Implications for tropospheric long-path absorption measurements, J. Geophys. Res., 100, 7397-7409, https://doi.org/10.1029/94jd03323, 1995b.

Fantechi, G., Vereecken, L., and Peeters, J.: The OH-initiated atmospheric oxidation of pinonaldehyde: Detailed theoretical study and mechanism construction, Phys. Chem. Chem. Phys., 4, 5795-5805, https://doi.org/10.1039/B205901K, 2002.

Fuchs, H., Bohn, B., Hofzumahaus, A., Holland, F., Lu, K. D., Nehr, S., Rohrer, F., and Wahner, A.: Detection of $\mathrm{HO}_{2}$ by laser-induced fluorescence: calibration and interferences from $\mathrm{RO}_{2}$ radicals, Atmos. Meas. Tech., 4, 1209-1225, https://doi.org/10.5194/amt-4-1209-2011, 2011.

Fuchs, H., Dorn, H.-P., Bachner, M., Bohn, B., Brauers, T., Gomm, S., Hofzumahaus, A., Holland, F., Nehr, S., Rohrer, F., Tillmann, R., and Wahner, A.: Comparison of $\mathrm{OH}$ concentration measurements by DOAS and LIF during SAPHIR chamber experiments at high $\mathrm{OH}$ reactivity and low NO concentration, Atmos. Meas. Tech., 5, 1611-1626, https://doi.org/10.5194/amt-5-1611-2012, 2012.

Fuchs, H., Hofzumahaus, A., Rohrer, F., Bohn, B., Brauers, T., Dorn, H.-P., Häseler, R., Holland, F., Kaminski, M., Li, X., Lu, K., Nehr, S., Tillmann, R., Wegener, R., and Wahner, A.: Experimental evidence for efficient hydroxyl radical regeneration in isoprene oxidation, Nat. Geosci., 6, 1023-1026, https://doi.org/10.1038/NGEO1964, 2013.

Fuchs, H., Acir, I. H., Bohn, B., Brauers, T., Dorn, H. P., Häseler, R., Hofzumahaus, A., Holland, F., Kaminski, M., Li, X., Lu, K., Lutz, A., Nehr, S., Rohrer, F., Tillmann, R., Wegener, R., and Wahner, A.: $\mathrm{OH}$ regeneration from methacrolein oxidation investigated in the atmosphere simulation chamber SAPHIR, Atmos. Chem. Phys., 14, 7895-7908, https://doi.org/10.5194/acp14-7895-2014, 2014.

Fuchs, H., Albrecht, S., Acir, I., Bohn, B., Breitenlechner, M., Dorn, H.-P., Gkatzelis, G. I., Hofzumahaus, A., Holland, F., Kaminski, M., Keutsch, F. N., Novelli, A., Reimer, D., Rohrer, F., Tillmann, R., Vereecken, L., Wegener, R., Zaytsev, A., Kiendler-Scharr, A., and Wahner, A.: Investigation of the oxidation of methyl vinyl ketone (MVK) by $\mathrm{OH}$ radicals in the atmospheric simulation chamber SAPHIR, Atmos. Chem. Phys., 18, 8001-8016, https://doi.org/10.5194/acp-18-8001-2018, 2018.

Fuchs, H., Rolletter, M., Blocquet, M., Kaminski, M., Bohn, B., Dorn, H.-P., Hofzumahaus, A., Holland, F., Li, X., Rohrer, F., Tillmann, R., Wegener, R., Kiendler-Scharr, A., and Wahner, A.: Atmospheric simulation chamber study: pinonaldehyde + $\mathrm{OH}$ - Gas-phase oxidation - product study [Data set], AERIS, https://doi.org/10.25326/G53K-WH75, 2020a.

Fuchs, H., Rolletter, M., Blocquet, M., Kaminski, M., Bohn, B., Dorn, H.-P., Hofzumahaus, A., Holland, F., Li, X., Rohrer, F., Tillmann, R., Wegener, R., Kiendler-Scharr, A., and Wahner, A.: Atmospheric simulation chamber study: pinonaldehyde + $\mathrm{OH}$ - Gas-phase oxidation - product study [Data set], AERIS, https://doi.org/10.25326/887C-F682, 2020b.

Galloway, M. M., Huisman, A. J., Yee, L. D., Chan, A. W. H., Loza, C. L., Seinfeld, J. H., and Keutsch, F. N.: Yields of oxidized volatile organic compounds during the $\mathrm{OH}$ radical initiated oxidation of isoprene, methyl vinyl ketone, and methacrolein under high-NO ${ }_{x}$ conditions, Atmos. Chem. Phys., 11, 10779-10790, https://doi.org/10.5194/acp-11-10779-2011, 2011.

Gautrois, M. and Koppmann, R.: Diffusion technique for the production of gas standards for atmospheric measurements, J. Chromatography A, 848, 239-249, https://doi.org/10.1016/S00219673(99)00424-0, 1999.

Glasius, M., Calogirou, A., Jensen, J., Hjorth, J., and Nielsen, C. J.: Kinetic study of gas-phase reactions of pinonaldehyde and structurally related compounds, Int. J. Chem. Kin., 29, 527-533, https://doi.org/10.1002/(sici)1097-4601(1997)29:7<527::Aidkin7>3.0.Co;2-w, 1997.

Guenther, A. B., Jiang, X., Heald, C. L., Sakulyanontvittaya, T., Duhl, T., Emmons, L. K., and Wang, X.: The Model of Emissions of Gases and Aerosols from Nature version 2.1 (MEGAN2.1): an extended and updated framework for modeling biogenic emissions, Geosci. Model Dev., 5, 1471-1492, https://doi.org/10.5194/gmd-5-1471-2012, 2012.

Hallquist, M., Wängberg, I., and Ljungström, E.: Atmospheric fate of carbonyl oxidation products originating from $\alpha$ pinene and $\Delta^{3}$-carene: determination of rate of reaction with $\mathrm{OH}$ and $\mathrm{NO}_{3}$ radicals, UV absorption cross sections, and vapor pressures, Environ. Sci. Technol., 31, 3166-3172, https://doi.org/10.1021/es970151a, 1997.

Hasson, A. S., Tyndall, G. S., and Orlando, J. J.: A product yield study of the reaction of $\mathrm{HO}_{2}$ radicals with ethyl peroxy $\left(\mathrm{C}_{2} \mathrm{H}_{5} \mathrm{O}_{2}\right)$, acetyl peroxy $\left(\mathrm{CH}_{3} \mathrm{C}(\mathrm{O}) \mathrm{O}_{2}\right)$, and acetonyl peroxy $\left(\mathrm{CH}_{3} \mathrm{C}(\mathrm{O}) \mathrm{CH}_{2} \mathrm{O}_{2}\right)$ radicals, J. Phys. Chem. A, 108, 5979-5989, https://doi.org/10.1021/jp048873t, 2004.

Hausmann, M., Brandenburger, U., Brauers, T., and Dorn, H.-P.: Detection of tropospheric $\mathrm{OH}$ radicals by long-path differentialoptical-absorption spectroscopy: Experimental setup, accuracy, and precision, J. Geophys. Res., 102, 16011-16022, https://doi.org/10.1029/97jd00931, 1997.

Hens, K., Novelli, A., Martinez, M., Auld, J., Axinte, R., Bohn, B., Fischer, H., Keronen, P., Kubistin, D., Nölscher, A. C., Oswald, R., Paasonen, P., Petäjä, T., Regelin, E., Sander, R., Sinha, V., Sipilä, M., Taraborrelli, D., Tatum Ernest, C., Williams, J., Lelieveld, J., and Harder, H.: Observation and modelling of $\mathrm{HO}_{x}$ radicals in a boreal forest, Atmos. Chem. Phys., 14, 8723-8747, https://doi.org/10.5194/acp-14-8723-2014, 2014.

Herckes, P., Engling, G., Kreidenweis, S. M., and Collett, J. L.: Particle size distributions of organic aerosol constituents during the 2002 Yosemite Aerosol Characterization Study, Environ. Sci. Technol., 40, 4554-4562, https://doi.org/10.1021/es0515396, 2006.

Hofzumahaus, A.: Measurement of Photolysis Frequencies in the Atmosphere, in: Analytical Techniques for Atmospheric Measurement, edited by: Heard, D. E., book section 9, pp. 406-500, https://doi.org/10.1002/9780470988510.ch9, 2006.

Holland, F., Hofzumahaus, A., Schäfer, J., Kraus, A., and Pätz, $\mathrm{H}$. W.: Measurements of $\mathrm{OH}$ and $\mathrm{HO}_{2}$ radical concentrations and photolysis frequencies during BERLIOZ, J. Geophys. Res., 108, 8246, https://doi.org/10.1029/2001JD001393, 2003.

Jacob, D. J., Field, B. D., Jin, E. M., Bey, I., Li, Q., Logan, J. A., and Yantosca, R. M.: Atmospheric acetone budget, J. Geophys. Res., 107, 4100, https://doi.org/10.1029/2001JD000694, 2002. 
Jaoui, M. and Kamens, R. M.: Gas phase photolysis of pinonaldehyde in the presence of sunlight, Atmos. Environ., 37, 18351851, https://doi.org/10.1016/S1352-2310(03)00033-5, 2003.

Jenkin, M. E., Saunders, S. M., and Pilling, M. J.: The tropospheric degradation of volatile organic compounds: A protocol for mechanism development, Atmos. Environ., 31, 81-104, https://doi.org/10.1016/S1352-2310(96)00105-7, 1997.

Jordan, A., Haidacher, S., Hanel, G., Hartungen, E., Märk, L., Seehauser, H., Schottkowsky, R., Sulzer, P., and Märk, T. D.: A high resolution and high sensitivity proton-transfer-reaction time-offlight mass spectrometer (PTR-TOF-MS), Int. J. Mass Spectrom., 286, 122-128, https://doi.org/10.1016/j.ijms.2009.07.005, 2009.

Kaminski, M., Fuchs, H., Acir, I.-H., Bohn, B., Brauers, T., Dorn, H.-P., Häseler, R., Hofzumahaus, A., Li, X., Lutz, A., Nehr, S., Rohrer, F., Tillmann, R., Vereecken, L., Wegener, R., and Wahner, A.: Investigation of the $\beta$-pinene photooxidation by $\mathrm{OH}$ in the atmosphere simulation chamber SAPHIR, Atmos. Chem. Phys., 17, 6631-6650, https://doi.org/10.5194/acp-176631-2017, 2017.

Kanakidou, M., Tsigaridis, K., Dentener, F. J., and Crutzen, P. J.: Human-activity-enhanced formation of organic aerosols by biogenic hydrocarbon oxidation, J. Geophys. Res., 105, 9243-9354, https://doi.org/10.1029/1999JD901148, 2000.

Karl, M., Dorn, H.-P., Holland, F., Koppmann, R., Poppe, D., Rupp, L., Schaub, A., and Wahner, A.: Product study of the reaction of $\mathrm{OH}$ radicals with isoprene in the atmosphere simulation chamber SAPHIR, J. Atmos. Chem., 55, 167-187, https://doi.org/10.1007/s10874-006-9034-x, 2006.

Kavouras, I. G., Mihalopoulos, N., and Stephanou, E. G.: Formation and gas/particle partitioning of monoterpenes photooxidation products over forests, Geophys. Res. Lett., 26, 55-58, https://doi.org/10.1029/1998g1900251, 1999.

Kim, S., Wolfe, G. M., Mauldin, L., Cantrell, C., Guenther, A., Karl, T., Turnipseed, A., Greenberg, J., Hall, S. R., Ullmann, K., Apel, E., Hornbrook, R., Kajii, Y., Nakashima, Y., Keutsch, F. N., DiGangi, J. P., Henry, S. B., Kaser, L., Schnitzhofer, R., Graus, M., Hansel, A., Zheng, W., and Flocke, F. F.: Evaluation of $\mathrm{HO}_{x}$ sources and cycling using measurement-constrained model calculations in a 2-methyl-3-butene-2-ol (MBO) and monoterpene (MT) dominated ecosystem, Atmos. Chem. Phys., 13, 20312044, https://doi.org/10.5194/acp-13-2031-2013, 2013.

Kwok, E. S. C. and Atkinson, R.: Estimation of hydroxyl radical reaction rate constants for gas-phase organic compounds using a structure-reactivity relationship: An update, Atmos. Environ., 29, 1685-1695, https://doi.org/10.1016/1352-2310(95)00069-B, 1995.

Larsen, B. R., Di Bella, D., Glasius, M., Winterhalter, R., Jensen, N. R., and Hjorth, J.: Gas-phase $\mathrm{OH}$ oxidation of monoterpenes: Gaseous and particulate products, J. Atmos. Chem., 38, 231-276, https://doi.org/10.1023/A:1006487530903, 2001.

Lew, M. M., Dusanter, S., and Stevens, P. S.: Measurement of interferences associated with the detection of the hydroperoxy radical in the atmosphere using laser-induced fluorescence, Atmos. Meas. Tech., 11, 95-109, https://doi.org/10.5194/amt-1195-2018, 2018.

Li, X., Rohrer, F., Hofzumahaus, A., Brauers, T., Häseler, R., Bohn, B., Broch, S., Fuchs, H., Gomm, S., Holland, F., Jäger, J., Kaiser, J., Keutsch, F. N., Lohse, I., Lu, K., Tillmann, R., Wegener,
R., Wolfe, G. M., Mentel, T. F., Kiendler-Scharr, A., and Wahner, A.: Missing gas-phase source of HONO inferred from Zeppelin measurements in the troposphere, Science, 344, 292-296, https://doi.org/10.1126/science.1248999, 2014.

Lindinger, W., Hansel, A., and Jordan, A.: On-line monitoring of volatile organic compounds at pptv levels by means of proton-transfer-reaction mass spectrometry (PTR-MS) - Medical applications, food control and environmental research, Int. J. Mass Spectrom., 173, 191-241, https://doi.org/10.1016/s01681176(97)00281-4, 1998.

Martinez, R. D., Buitrago, A. A., Howell, N. W., Hearn, C. H., and Joens, J. A.: The near U.V. absorption spectra of several aliphatic aldehydes and ketones at $300 \mathrm{~K}$, Atmos. Environ., 26, 785-792, https://doi.org/10.1016/0960-1686(92)90238-G, 1992.

Matsumi, Y., Comes, F. J., Hancock, G., Hofzumahaus, A., Hynes, A. J., Kawasaki, M., and Ravishankara, A. R.: Quantum yields for production of $\mathrm{O}\left({ }^{1} \mathrm{D}\right)$ in the ultraviolet photolysis of ozone: Recommendation based on evaluation of laboratory data, J. Geophys. Res.-Atmos., 107, ACH1-1-ACH1-12, https://doi.org/10.1029/2001jd000510, 2002.

MCM: Master Chemical Mechanism, available at: http://mcm. leeds.ac.uk/MCM/ (last access: 4 March 2020), 2017.

Mérienne, M. F., Jenouvrier, A., and Coquart, B.: The $\mathrm{NO}_{2}$ absorption spectrum. I: Absorption cross-sections at ambient temperature in the 300-500 nm region, J. Atmos. Chem., 20, 281-297, https://doi.org/10.1007/bf00694498, 1995.

Moortgat, G., Wirtz, K., Hjorth, J., Ljungstrom, E., Ruppert, L., Hayman, G., and Mellouki, W.: "Evaluation of radical sources in atmospheric chemistry through chamber and laboratory studies", Final report on the EU project "RADICAL", Report EUR 20254 EN, 2002.

Müller, K., Haferkorn, S., Grabmer, W., Wisthaler, A., Hansel, A., Kreuzwieser, J., Cojocariu, C., Rennenberg, H., and Herrmann, H.: Biogenic carbonyl compounds within and above a coniferous forest in Germany, Atmos. Environ., 40, 81-91, https://doi.org/10.1016/j.atmosenv.2005.10.070, 2006.

Novelli, A., Vereecken, L., Bohn, B., Dorn, H.-P., Gkatzelis, G. I., Hofzumahaus, A., Holland, F., Reimer, D., Rohrer, F., Rosanka, S., Taraborrelli, D., Tillmann, R., Wegener, R., Yu, Z., KiendlerScharr, A., Wahner, A., and Fuchs, H.: Importance of isomerization reactions for $\mathrm{OH}$ radical regeneration from the photooxidation of isoprene investigated in the atmospheric simulation chamber SAPHIR, Atmos. Chem. Phys., 20, 3333-3355, https://doi.org/10.5194/acp-20-3333-2020, 2020.

Noziére, B., Barnes, I., and Becker, K.-H.: Product study and mechanisms of the reactions of $\alpha$-pinene and of pinonaldehyde with OH radicals, J. Geophys. Res., 104, 23645-23656, https://doi.org/10.1029/1999JD900778, 1999.

Otkjær, R. V., Jakobsen, H. H., Tram, C. M., and Kjaergaard, H. G.: Calculated Hydrogen Shift Rate Constants in Substituted Alkyl Peroxy Radicals, J. Phys. Chem. A,, 122, 8665-8673, https://doi.org/10.1021/acs.jpca.8b06223, 2018.

Peeters, J., Vereecken, L., and Fantechi, G.: The detailed mechanism of the $\mathrm{OH}$-initiated atmospheric oxidation of $\alpha$-pinene: a theoretical study, Phys. Chem. Chem. Phys., 3, 5489-5504, https://doi.org/10.1039/B106555F, 2001.

Peeters, J., Müller, J.-F., Stavrakou, T., and Nguyen, V. S.: Hydroxyl radical recycling in isoprene oxidation driven by hydrogen bonding and hydrogen tunneling: The upgraded 
LIM1 mechanism, J. Phys. Chem. A, 118, 8625-8643, https://doi.org/10.1021/jp5033146, 2014.

Plewka, A., Gnauk, T., Bruggemann, E., and Herrmann, H.: Biogenic contributions to the chemical composition of airborne particles in a coniferous forest in Germany, Atmos. Environ., 40, S103-S115, https://doi.org/10.1016/j.atmosenv.2005.09.090, 2006.

Praske, E., Crounse, J. D., Bates, K. H., Kurten, T., Kjaergaard, H. G., and Wennberg, P. O.: Atmospheric fate of methyl vinyl ketone: Peroxy radical reactions with $\mathrm{NO}$ and $\mathrm{HO}_{2}$, J. Phys. Chem. A, 119, 4562-4572, https://doi.org/10.1021/jp5107058, 2015.

Rissanen, T., Hyotylainen, T., Kallio, M., Kronholm, J., Kulmala, M., and Rikkola, M. L.: Characterization of organic compounds in aerosol particles from a coniferous forest by GC-MS, Chemosphere, 64, 1185-1195, https://doi.org/10.1016/j.chemosphere.2005.11.079, 2006.

Rohrer, F. and Brüning, D.: Surface $\mathrm{NO}$ and $\mathrm{NO}_{2}$ mixing ratios measured between $30^{\circ} \mathrm{N}$ and $30^{\circ} \mathrm{S}$ in the Atlantic region, J. Atmos. Chem., 15, 253-267, https://doi.org/10.1029/97JD01853, 1992.

Rohrer, F., Bohn, B., Brauers, T., Brüning, D., Johnen, F.-J., Wahner, A., and Kleffmann, J.: Characterisation of the photolytic HONO-source in the atmosphere simulation chamber SAPHIR, Atmos. Chem. Phys., 5, 2189-2201, https://doi.org/10.5194/acp5-2189-2005, 2005.

Rolletter, M., Kaminski, M., Acir, I.-H., Bohn, B., Dorn, H.-P., Li, X., Lutz, A., Nehr, S., Rohrer, F., Tillmann, R., Wegener, R., Hofzumahaus, A., Kiendler-Scharr, A., Wahner, A., and Fuchs, H.: Investigation of the $\alpha$-pinene photooxidation by $\mathrm{OH}$ in the atmospheric simulation chamber SAPHIR, Atmos. Chem. Phys., 19, 11635-11649, https://doi.org/10.5194/acp-19-116352019, 2019.

Satsumabayashi, H., Nishizawa, H., Yokouchi, Y., and Ueda, H.: Pinonaldehyde and some other organics in rain and snow in central Japan, Chemosphere, 45, 887-891, https://doi.org/10.1016/s0045-6535(01)00024-8, 2001.

Saunders, S. M., Jenkin, M. E., Derwent, R. G., and Pilling, M. J.: Protocol for the development of the Master Chemical Mechanism, MCM v3 (Part A): tropospheric degradation of nonaromatic volatile organic compounds, Atmos. Chem. Phys., 3, 161-180, https://doi.org/10.5194/acp-3-161-2003, 2003.

Schlosser, E., Bohn, B., Brauers, T., Dorn, H.-P., Fuchs, H., Häseler, R., Hofzumahaus, A., Holland, F., Rohrer, F., Rupp, L. O., Siese, M., Tillmann, R., and Wahner, A.: Intercomparison of two hydroxyl radical measurement techniques at the atmosphere simulation chamber SAPHIR, J. Atmos. Chem., 56, 187-205, https://doi.org/10.1007/s10874-006-9049-3, 2007.

Schwantes, R. H., Emmons, L. K., Orlando, J. J., Barth, M. C., Tyndall, G. S., Hall, S. R., Ullmann, K., St. Clair, J. M., Blake, D. R., Wisthaler, A., and Bui, T. P. V.: Comprehensive isoprene and terpene gas-phase chemistry improves simulated surface ozone in the southeastern US, Atmos. Chem. Phys., 20, 3739-3776, https://doi.org/10.5194/acp-20-3739-2020, 2020.
Stutz, J., Kim, E. S., Platt, U., Bruno, P., Perrino, C., and Febo, A.: UV-visible absorption cross sections of nitrous acid, J. Geophys. Res.-Atmos., 105, 14585-14592, https://doi.org/10.1029/2000jd900003, 2000.

Tadić, J., Juranić, I., and Moortgat, G. K.: Pressure dependence of the photooxidation of selected carbonyl compounds in air: nbutanal and n-pentanal, J. Photochem. Photobiol. A, 143, 169179, https://doi.org/10.1016/S1010-6030(01)00524-X, 2001.

Troe, J.: Are primary quantum yields of NO2 photolysis at $\lambda \leq$ $398 \mathrm{~nm}$ smaller than unity?, Z. Phys. Chem., 214, 573-581, https://doi.org/10.1524/zpch.2000.214.5.573, 2000.

Vereecken, L. and Nozière, B.: H migration in peroxy radicals under atmospheric conditions, Atmos. Chem. Phys., 20, 7429-7458, https://doi.org/10.5194/acp-20-7429-2020, 2020.

Vereecken, L. and Peeters, J.: Enhanced H-atom abstraction from pinonaldehyde, pinonic acid, pinic acid, and related compounds: theoretical study of C-H bond strengths, Phys. Chem. Chem. Phys., 4, 467-472, https://doi.org/10.1039/B109370C, 2002.

Vereecken, L. and Peeters, J.: Decomposition of substituted alkoxy radicals-part I: a generalized structure-activity relationship for reaction barrier heights, Phys. Chem. Chem. Phys., 11, 90629074, https://doi.org/10.1039/B909712K, 2009.

Vereecken, L., Müller, J. F., and Peeters, J.: Low-volatility poly-oxygenates in the $\mathrm{OH}$-initiated atmospheric oxidation of $\alpha$-pinene: impact of non-traditional peroxyl radical chemistry, Phys. Chem. Chem. Phys., 9, 5241-5248, https://doi.org/10.1039/B708023A, 2007.

Whalley, L. K., Blitz, M. A., Desservettaz, M., Seakins, P. W., and Heard, D. E.: Reporting the sensitivity of laser-induced fluorescence instruments used for $\mathrm{HO} 2$ detection to an interference from $\mathrm{RO}_{2}$ radicals and introducing a novel approach that enables $\mathrm{HO}_{2}$ and certain $\mathrm{RO}_{2}$ types to be selectively measured, Atmos. Meas. Tech., 6, 3425-3440, https://doi.org/10.5194/amt-6-3425-2013, 2013.

Xu, L., Møller, K. H., Crounse, J. D., Otkjær, R. V., Kjaergaard, H. G., and Wennberg, P. O.: Unimolecular Reactions of Peroxy Radicals Formed in the Oxidation of $\alpha$-Pinene and $\beta$-Pinene by Hydroxyl Radicals, J. Phys. Chem. A, 123, 1661-1674, https://doi.org/10.1021/acs.jpca.8b11726, 2019.

Yu, J. Z., Griffin, R. J., Cocker, D. R., Flagan, R. C., Seinfeld, J. H., and Blanchard, P.: Observation of gaseous and particulate products of monoterpene oxidation in forest atmospheres, Geophys. Res. Lett., 26, 1145-1148, https://doi.org/10.1029/1999g1900169, 1999. 